\title{
An Intelligent Framework for Analyzing the Feasible Modes of Transportation in Metropolitan Cities: A Hybrid Multicriteria Approach
}

\author{
Praveen Ranjan Srivastava $\mathbb{D}^{1},{ }^{1}$ Zuopeng (Justin) Zhang ${ }^{\mathbb{D}},{ }^{2}$ Prajwal Eachempati $\mathbb{D}^{1},{ }^{1}$ \\ and Hongbo Lyu $\mathbb{D}^{3}$ \\ ${ }^{1}$ Indian Institute of Management (IIM), Rohtak, India \\ ${ }^{2}$ Department of Management, Coggin College of Business, University of North Florida, Jacksonville, FL, USA \\ ${ }^{3}$ Zhejiang Wanli University, Ningbo, China \\ Correspondence should be addressed to Hongbo Lyu; lvhongbo@zwu.edu.cn
}

Received 12 December 2020; Revised 24 January 2021; Accepted 16 February 2021; Published 1 March 2021

Academic Editor: Chi-Hua Chen

Copyright (c) 2021 Praveen Ranjan Srivastava et al. This is an open access article distributed under the Creative Commons Attribution License, which permits unrestricted use, distribution, and reproduction in any medium, provided the original work is properly cited.

\begin{abstract}
The paper aims to build a hybrid personalized multicriteria model in the Indian transportation industry to identify the most feasible transport mode suitable for commuters' customized preferences. A hybrid multicriterion model, i.e., Fuzzy Analytical Hierarchy Process (AHP), was used to compute the criteria weights, which were subsequently analyzed by three approaches, namely, Technique for Order of Preference by Similarity to Ideal Solution (TOPSIS), Fuzzy TOPSIS, Evaluation Based on Distance from Average Solution (EDA), and Interpretive Ranking Process (IRP). The case of an Indian metropolitan city, Hyderabad, is taken to illustrate the proposed approach. The paper highlights the following transport modes: metropolitan train (unconventional mode) and conventional modes such as the car, public bus transport, and bikes for Hyderabad. Furthermore, sensitivity analysis is performed to identify the consistency in ranking with variation in weights, and the Ensemble Ranking and transportation experts validate the rankings.
\end{abstract}

\section{Introduction}

India's transportation industry has been growing steadily at a Cumulative Annual Growth Rate (CAGR) of $5.9 \%$ and is majorly dominated by roadways. India has a road network of 5.23 million kilometers and is expected to grow at a CAGR of $7 \%$ in the next five years [1]. It is also reported by the Mordor Intelligence Report [1] that more than $50 \%$ of the freight and $90 \%$ of the passengers are found to commute by road. This may contribute to a manifold increase in road traffic, and there is a need for more effective traffic management and vehicle routing. Passengers, especially across such trafficintensive routes, find it challenging to travel by conventional transport modes like public buses within the city. The development of cars due to the proliferation of automobile technology is increasing by leaps and bounds. However, the notion of cars is not affordable and accessible to many, which prompts the need to search for more available modes of transport, which are cost-effective, environmentally less damaging, safe, and more affordable. In the light of this scenario, the metro train alternative is explored and analyzed for viability for transporting passengers across long distances within the confines of a city with minimal damage to the environment and nominal ticket rates.

Existing decision-making systems do not consider the customized preferences of the passengers and the transport planners to provide an automated decision regarding the vehicle mode is feasible, which is essential for a developing country and a price-sensitive market like India. Moreover, any country's Central government accords paramount importance to the safety and security of the conventional modes of transportation apart from analyzing the economic 
feasibility and the environmental sustainability. Some factors like political consequences, cost-effectiveness, and the impact on the environment [2] are prioritized while choosing the best-suited vehicle mode. The simulation model develops various permutations and combinations to examine the possibilities. It is envisaged that the transport authorities and the planners would benefit from the study to meet the growing demand from passengers.

In this context, there is a need to choose a vehicle mode that satisfies all the stakeholders (users, operators, planners, and policymakers). The choice must also rationalize all the stakeholders' conflicting perspectives for which the hybrid multicriteria model is adopted in this paper. The PESTLE framework (Political, Economic, Social, Technological, Legal, and Ecological) is adopted in this paper to identify the most suitable transport alternative with due consideration for all dimensions. This framework is appropriate since different stakeholders consider different perspectives. Users consider mainly the economic and social perspectives to decide on the choice of the vehicle mode. If the choice is studied ony from a user perspective, other (political, technological, and legel) considerations may not be factored in, thus resulting in a mopic viewpoint. However, in the context of a metropolitan city and for a problem statement like the vehicle mode choice, there is a need to address all the PESTLE factors to make a more informed decision. This is because transport operators, city planners, and policymakers also consider other political, legal, technological, and environmental concerns for promoting a vehicle mode. Hence, to cater to all stakeholders and capture the plethora of factors considered in this paper, a multistakeholder perspective is adopted without confining to a single perspective. The research objectives or motives of this paper are defined as follows:

\subsection{Research Motives.}

To identify and evaluate the significant factors from the internal and external environments that influence India's transport mode decision

To evaluate and identify the best-suited transport modes from a multistakeholder perspective (benefitting passengers, operators, planners, and policymakers) using a hybrid multicriteria model

To provide practical and policy implications to the stakeholders

Since there are many factors/criteria to be considered which may involve evaluating the benefit-cost analysis of the elements, a multicriteria [3-6] model is formulated. The model evaluates the trade-off of different factors influencing the vehicle selection decisions to provide suitable weightage to prioritize the elements and identify the most feasible alternative. The order of precedence of factors may vary from passenger to passenger, and hence, the model factors in priorities of a single passenger scenario. In such circumstances, there is a need to have intelligent decision systems that can evaluate the criteria as well as choose the best alternative, among others. Thus, in the process, a Hybrid
Multicriterion Fuzzy AHP-TOPSIS/Fuzzy TOPSIS/EDA/ Ensemble Ranking model $[7,8]$ is simulated. The model evaluates the set criteria and the available alternatives after considering the preference of passengers extracted from primary data and assigns weights to the factors that are input for the ranking of vehicle transport modes. The rest of the paper is structured as follows. The literature review is elucidated in Section 2. The research methodology adopted for the hybrid multicriteria model is discussed in Section 3, followed by the proposed model and data collection in Section 4. The application of the proposed model is then illustrated and analyzed in Section 5. Finally, the study's implications are presented in Section 6, and the investigation is concluded in Section 7. The references are then stated.

\section{Review of Literature}

The review of the existing literature involves identifying the factors and subfactors influencing the vehicle mode selection (Section 2.1) and reviewing the existing research in the domain (Section 2.2).

2.1. Literature Review of Factors and Subfactors Influencing Selection of a Transport Mode. The existing studies that analyze the passenger preferences categorize the factors into (i) Political factors, (ii) Economic Factors, (iii) Social Factors, (iv) Technological Factors, (v) Legal Factors, and (vi) Environmental factors [2]. Political factors are further subdivided into Political Stability and Government Policy. Economic factors include Duties and Taxes, Economic Growth, Unemployment, and Cost Efficiency, while Social Factors include Health, Safety, and Security. Technological factors define vehicle metrics like Maintenance and Fuel Efficiency, while the Legal factors are Restricted Movement and Legislation. Environmental factors are Air Pollution and Noise Pollution, as depicted in Figure 1.

The factors and subfactors that influence the selection of an available transport mode are as follows:

2.1.1. Political Factors [9]. The political situation is a critical factor that determines the choice of transport. The enforcement and amendments made to significant transportation policies, including employment laws for staff, environmental legislation, vehicle taxation laws, health, and safety norms [10], decide as to which transport mode is feasible. The political factors are further subdivided into

(1) Political stability [10]: political stability is a measure of the state of political affairs in a region and the ruling political party's power. Political disputes may impact routes' functioning and may disrupt the traffic on the roads; hence, the mode of transport is affected. This is common in metropolitan and politically active cities in India, impacting vehicles' operation due to road strikes.

(2) Government policy: the government policy issues refer to the introduction of competing for public 


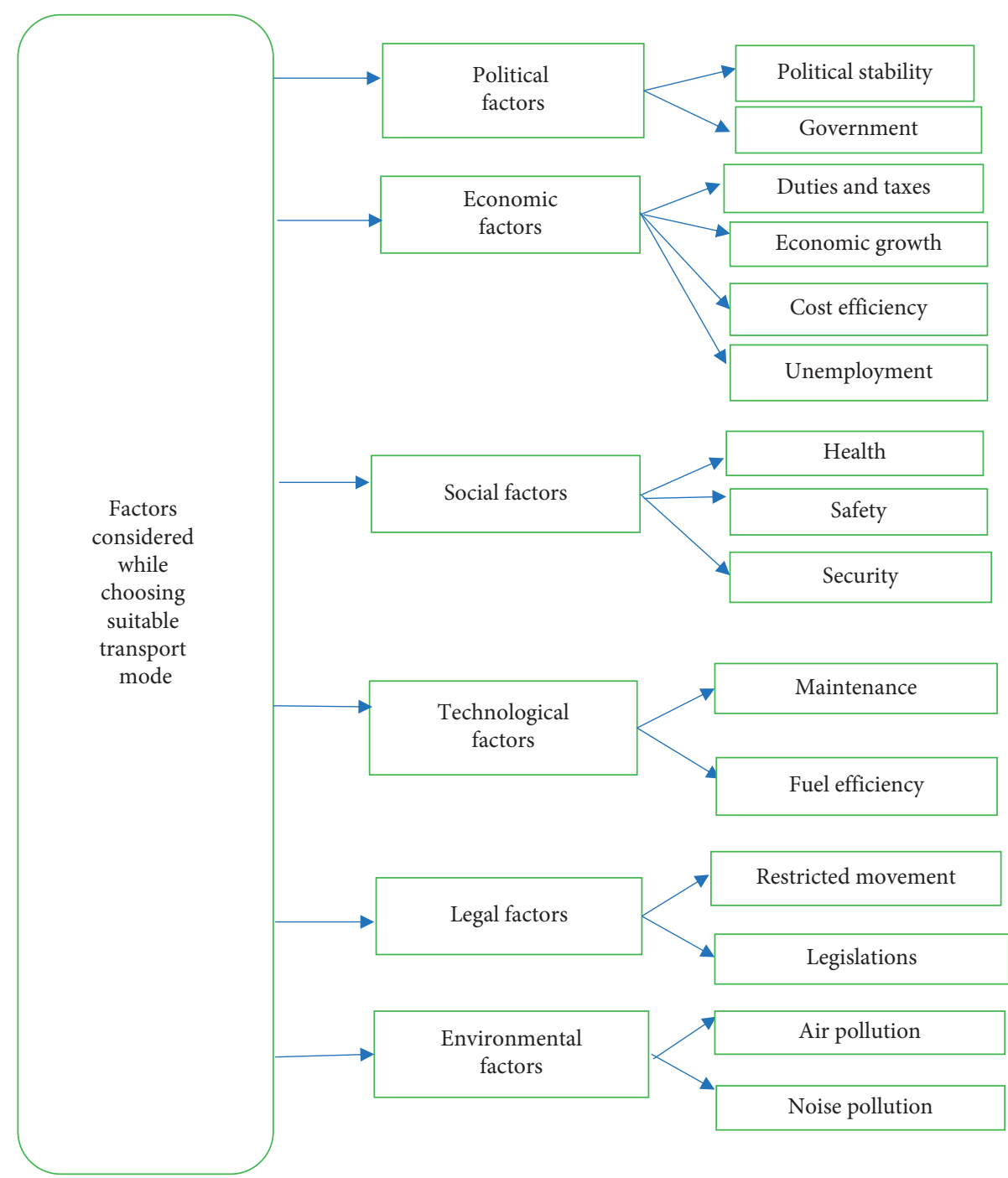

FIGURE 1: Factors that influence the vehicle mode selection.

transports and the implementation of newer unconventional modes of transport. The Ministry of Transportation and Roadways promulgates legislations to different route modes of transport, which impacts the city's route landscape and, in turn, the choice of transport.

2.1.2. Economic Factors [11]. However, another set of factors that influences the feasibility of transport modes are economic factors. The financial issues include

(1) Duties and taxes [12]: the duties and fees levied on vehicles like toll tax, road tax, etc., impact the cars' functioning across the allocated routes. Passengers prefer routes and modes of transport with minimal charges levied on the vehicles, which influences their decision-making.

(2) Economic growth: the growth of the economy influences lifestyle changes, and this, in turn, impacts the choice of the transportation mode.
(3) Cost efficiency [13]: cost efficiency is a metric that quantifies the cost incurred for adopting a mode of transport, viz-viz, the distance and time taken to travel to a place across a particular route. Routes and modes of transportation that are more cost-effective are, therefore, preferred.

(4) Workforce utilization/unemployment rate: the transportation industry is infrastructure-dependent and highly labor-intensive. Alternative transport modes especially are highly dependent on the lowcost labor market. At the same time, conventional transport modes cannot be completely phased out since the livelihood of the drivers and the staff (employees) will be disrupted.

2.1.3. Social Factors [14]. Social factors include attributes like demography, education level, and income with the perception of health, safety, and security [15], which directly impact the transportation industry. Social factors are grouped into the following subfactors in the paper: 
(1) Health: the health conditions and issues faced by passengers and drivers influence the continuation of transportation modes' operation.

(2) Safety: the safety of the vehicle and the route adopted are both critical to choose a suitable vehicle mode.

(3) Security: the measure of the risk exposure of the passengers and the staff to criminal activities like physical harassment, robbery, stealing, etc., is security. Passengers intuitively prefer highly secure modes of transport.

2.1.4. Technological Factors [16]. The evolution of technology developed ways to quantify the maintenance of vehicles. There are several technological factors of which the factors "upgradation in fuel technology" and the "rate of fuel efficiency" [17] are significant drivers of choosing the best mode of transport. The operation and the maintenance of the various kinds of unconventional transport modes are technology dependent, and their performance is quantified in terms of fuel efficiency. This, in turn, prompts the need for fuel technology upgradation. Furthermore, this factor is also intuitively considered necessary at a layman level to choose a particular vehicle mode and is hence incorporated in the multicriteria model to provide customized vehicle alternative recommendations. Technological factors define vehicle metrics like Maintenance and Fuel Efficiency as follows:

(1) Maintenance: the extent to which a vehicle is damage-free and is in good condition for operability on the roads is called maintenance. Maintenance is also related to the safety of the vehicle and is of high importance.

(2) Fuel efficiency: the distance travelled by a vehicle viza-viz the fuel consumed to complete the trip is a measure of how fuel-efficient the vehicle is. The higher the value, the more economical the vehicle will be.

2.1.5. Legal Factors [18]. Laws governing the transport authorities and vehicle plying policies are essential to determine the transport mode. Legal factors can be:

(1) Restricted movement: the legal factors deal with regulatory operating bodies, statutory rules, and the policies regarding "Restricted Movement" [19] considered to analyze the feasibility of a vehicle mode. Banning some unconventional modes of transport as well as imposing restrictions on the authorities in their operation on specific roads.

(2) Legislation: the traffic routing policies and the extent of stringent measures taken to administer the functioning of the unconventional modes of transport also influence vehicle mode choice.

2.1.6. Environmental Factors [20]. The ecological dimension is captured by the factor of environmental pollution [21]. Pollution is subclassified into:
(1) Air pollution: the vehicle modes that release poisonous pollutants into the air like carbon monoxide and nitrous oxides have a damaging effect on the environment leading to hazards like global warming, acid rain, and ozone layer depletion if not curbed at early stages.

(2) Noise pollution: the vehicles also can contribute to a major portion of the community noise, particularly disruptive in the residential areas. The traffic flow speed is directly proportional to the number of decibels of noise emitted and needs to be controlled.

The existing studies on vehicle alternative selection are discussed below:

2.2. Existing Research on Vehicle Alternative Selection. Christiansen [9] studies how political factors impact the choice of transportation mode. The Hierarchial Ordinary Least Squares technique has been adopted to test the hypothesis. It can be inferred that political considerations are significant, and thus, policies need to be analyzed in further detail to choose a suitable vehicle mode. Zhou and Zhang [12] examine the impact of environmental factors on the vehicle mode to opt for. A systematic literature review is performed. The fuel efficiency and minimization of carbon emissions are essential factors to consider.

Gössling [22] investigates the challenges of introducing e-scooters in ten major cities by content analysis of Internet searches, print media, TV, and radio websites. Policy concerns related to the implementation of this transport mode are assessed. The paper recommends urban planners to introduce policies regarding maximum speed, bicycle infrastructure, and limit the number of licensed operators.

Daisy et al. [23] advocate a cohort-based approach to analyze the patterns of trips, to propose a suitable transport mode choice factoring in socio-demographics, trip attributes, and land-use patterns using a multinomial logit model. It is found that sociodemographic characteristics and tour attributes are significant determinants of travel behavior.

Ashmore et al. [24] utilized two tenets of the Hofstede cross-cultural indices-power differential and individualism versus collectivism-to develop the transport choice model through qualitative deductive thematic analysis. The significant differences between the cross-cultural group symbolizes the importance of symbolism and culture in transport choice.

Tarabay and Abou-Zeid [25] investigate the future of ride-sharing services like Uber and Careem by the American University of Beirut, Lebanon. They developed a hybrid choice model that predicts the choice between traditional modes of transport to ride-sourcing services for social/ recreational trips in Lebanon. It is found that the factors influencing the switching choice are: door-to-door travel time, pickup waiting time, one-way fares, and individual differences in perceptions and attitudes toward ridesourcing services. 
Van Ristell et al. [26] analyze the traffic and environmental factors impacting school-going children's transport choice in England. Multinomial logit modelling and mixed multinomial logit modelling are adopted. It is suggested to advocate the "nearest school" policy, wherein students are admitted to schools in their proximity to prevent the rise in carbon-dioxide emissions and for cost-effectiveness.

Stoilova [16] studies the influence of technological factors on why some vehicle modes are preferred. Multicriteria methods like Fuzzy AHP and Promethee are adopted. Factors like fuel efficiency and updating fuel technology are found to be significant. Tian et al. [21] evaluated the impact of pollution on choosing a vehicle mode. A hybrid SBMDEA model is adopted. Vehicles with the least impact on pollution are preferred.

Roorda et al., [27] examine the factors influencing the choice of the transport mode. The nested Logit approach is implemented. There is a need to adopt safer and eco-friendly vehicle modes.

Jian et al. [28] aim to identify the factors that influence vehicle mode selection. The Spatial Hazard based model is adopted. The model with the best fit is chosen.

Luo et al. [29] study the importance of environmental factors. Model Predictive Control (MPC) framework is adopted. It is found that the most fuel-efficient vehicle is to be chosen, emphasizing the importance of environmental factors.

Chen and Wang [30] study how political factors like taxation laws impact transportation mode choice. Stochastic processes are adopted. Policies need to be analyzed differently for variable demand in further detail to choose a suitable vehicle mode.

Onstein et al. [18] aim to determine the role of legislations governing vehicles. This paper proposes a Best-Worst method. Legislations play an essential role.

To study how fuel efficiency impacts vehicle mode, binary logit models were adopted by Krishna et al. [17]. Their study revealed that the more the vehicle is fuel-efficient, the higher is the probability of being preferred.

Böcker et al. [31] investigate the transport mode choices of older people in the Netherlands. Zero-inflated negative binomial models and multinomial logit regression models are adopted. Older people are encouraged to use environmentally friendly transport modes.

Furthermore, the viability of an unconventional mode of transport, namely, e-bike share vehicle, is assessed by Campbell et al. [32] in China. A multinomial logit model is used. E-bike-share is found to be a more viable mode of transportation than bikes, an already existing transport mode in China.

Chee and Fernandez [33] study the transport mode choice in Penang, Malaysia. Surveys and questionnaires are used for the qualitative study. Private transport is found to be the predominant choice for commuters.

Donald et al. [34] analyze the psychological factors influencing the transport choice. Structured Equation Modelling was adopted. The use of private transport modes like the car is driven by intention and habit, while public modes are influenced solely by purpose.
Gebeyehu and Takano [35] examine that the transport mode choice in Addis Ababa is being reviewed. The ordered logit model was adopted. Fare, convenience, and frequency were the main factors for the bus as the transport mode in Addis Ababa.

The transport preferences of school-going children were analyzed by Kamargianni et al. [36]. A multinomial probit approach was adopted. The value for more eco-friendly alternatives like bicycling is emphasized over the bus.

Madhuwanthi et al. [37] analyze the travel behavior of Srilankan citizens. Multinomial Factor Analysis is implemented. Income, vehicle ownership, safety, and comfort are the crucial factors determining vehicle choice.

Transportation mode choice is investigated in Kharagpur and Asansol by Majumdar et al. [38] Exploratory Factor Analysis (EFA) is adopted. Bicycle is found to be a feasible alternative mode.

Santos et al. [39] examine the factors that influence the modal split in European countries using regression analysis. A significant negative correlation is found between private vehicle modes like cars and public transport (bus). The transport mode patterns for young adults are investigated [40]. Content analysis was performed using N-Vivo. The use of private transport modes like the bicycle is encouraged.

The above studies adopt existing choice models to identify the best-suited vehicle mode in respective country scenarios. However, there are some limitations in the choice of the methodology used.

These limitations are thus discussed below:

2.3. Research Gap. The above studies consider single or multiple factors for determining the choice of vehicle selection. However, a multifactor approach is not adopted to analyze the cumulative impact of all the factors considered for the transport choice decision. Determining the essential factors will help take proactive steps by road transport authorities to provide transport services at subsidized rates to retain frequent passengers.

Figure 2 illustrates the limitations in the existing studies. Firstly, the vehicle mode selection problem is not explored in an Indian metropolitan city context where there are multiple conventional and unconventional transport modes, and there is a need to understand the commuter's decision to choose the relevant mode. Furthermore, there is an interplay of multiple factors by conflicting stakeholders that was not captured in such a context.

Secondly, since a single factor is not sufficient to decide on the most feasible transport choice, there is a need to implement a multifactor approach to capture commuters' personalized preferences. Furthermore, existing choice models only capture the economic perspective of the choice of transport mode while other dimensions like political, social, and ecological factors are not considered. Furthermore, in a multistakeholder and hierarchical scenario where multiple conflicting objectives are applicable, there is a need for a more robust model to capture all the factors influencing the choice of the vehicle mode. Though there are some existing multicriteria approaches to make such decisions, 


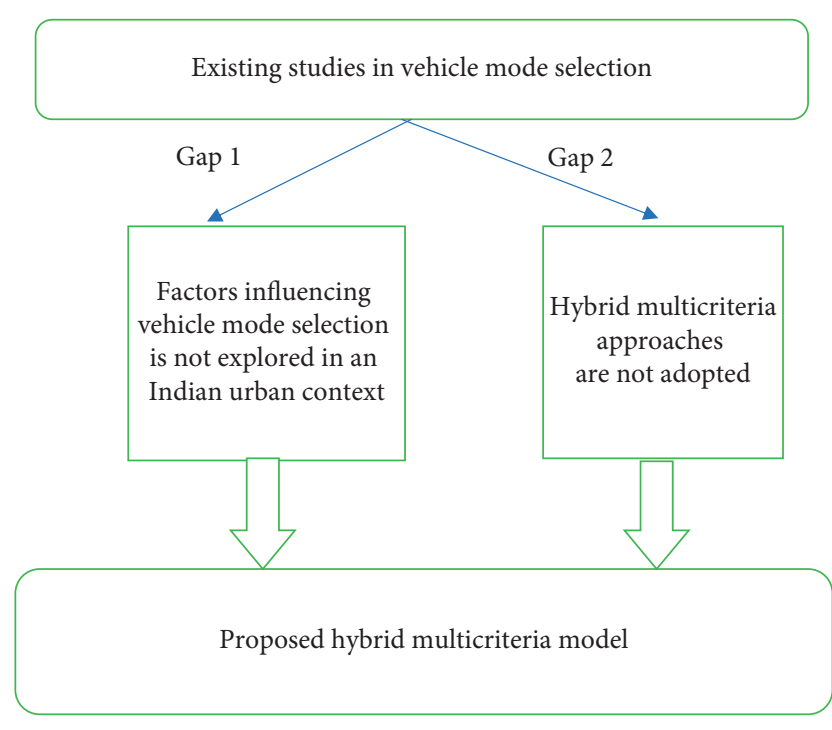

FIGURE 2: Research gaps.

there is a need to validate these approaches' outcome and perform a sensitivity analysis for further whetting the results. A hybrid multicriteria model that computes weights shows ranking, and validation using different multicriteria methods can provide a more optimized decision.

For overcoming the above limitations, a hybrid multicriteria model is adopted in the paper. The data collection procedure and research methodology adopted are discussed in Section 3.

\section{Data Collection and Methodology}

This section elucidates the data collection procedure (Section 3.2) and the research methodology adopted (Sections 3.3-3.6) in the paper. The rationale for choosing the method is detailed below:

3.1. Rationale for Methodology (PESTLE Framework and Hybrid Multicriteria Model). Existing frameworks like the SWOT capture the strengths, weaknesses, opportunities, and threats but do not factor in the ecological and the social dimensions. The different transport's survivability is driven by several external factors like government policies, carbon footprint, unfavorable laws, and constantly updating technologies. The PESTLE framework [41] is highly suitable and is adopted to capture this plethora of dimensions.

PESTLE Analysis framework stands for, Political, Economic, Social, Technological, Legal, and Environmental factors within the system to aid decision-making.

Furthermore, although there are existing techniques like choice models [36] to identify the best alternative, in the above scenario of choosing a suitable vehicle alternative mode, hybrid multicriteria methods are adopted. This is because choice models only provide alternatives from the point of view of minimizing costs. However, other dimensions like social, environmental, and political dimensions are not captured to provide the best alternative by choice models. This is needed in the above scenario for effective implementation of the PESTLE framework.

Secondly, there is a need to identify a suitable vehicle alternative from a host of conflicting objectives across stakeholders and across multiple hierarchy levels (criteria are further subdivided into subcriteria).

Thus, the hybrid multicriteria model is recommended over state-of-the-art choice models [26] and hence adopted in the paper.

Fuzzy AHP is adopted to compare the factors and alternatives by computing fuzzy scores assigning weights to the criteria. This methodology is very useful for multiple criteria decision-making in uncertain environments where the relative importance of factors influencing the transport mode cannot be assigned a crisp score. However, a fuzzy score with lower, medium, and higher bounds can be estimated for the factors. Hence, Fuzzy AHP is adopted. This Ranking is accomplished by Technique for Order of Preference by Similarity to Ideal Solution (TOPSIS) [42] by structuring the problem, conducting analysis, and enabling comparison and ranking. TOPSIS decides that the bestranked solution is one that is geometrically closest to the positive ideal solution (PIS) and farthest from the perfect negative solution (NIS). However, in scenarios where accurate comparisons cannot be handled, the fuzzy TOPSIS model is adopted to rank the vehicles. To perform maximization of beneficial factors and minimize the nonbeneficial factors, the Evaluation Based on Distance from the Average (EDA) approach for ranking of vehicles is applied.

Overall, to present a consolidated picture of the various rankings and to arrive at a robust consensus ranking to choose the most feasible vehicle mode, the novel Ensemble Ranking [43] technique is adopted.

Thus, a hybrid approach [44] is envisaged to accomplish the objectives of this paper.

The methodology adopted is divided into the following phases:

3.2. Phase 1: Data Collection. To analyze the alternative modes of transport in the metropolitan city of Hyderabad, initially, the data collection phase was initiated. A "complete participation" interview approach [45] was adopted where live interviews with the passengers and drivers were conducted in the areas defined above to develop an understanding of the traffic flow statistics, day-to-day operations, and various merits and demerits of the modes of transports. To corroborate the findings, one-to-one interviews were conducted with the various stakeholders-the transport authority staff, drivers, and frequent passenger and logistics and operations researchers to identify the significant issues. The drivers and other stakeholders across the particular routes are selected. Inputs are from legal authorities from the head office of the Road Traffic Authority (RTA) situated in Hyderabad, Telangana. The expert academics whose participation was solicited were top authorities on operations research. The interviews posed categorical questions initially to the stakeholders to give their opinions on which transport mode is better based on criteria like commuting time, fuel 
efficiency, and environmental friendliness on a scale of 1-9. The questionnaire is enclosed below in the Appendix.

The above responses provided by the passengers are then transformed to fuzzy scores according to the fuzzy scale provided in Table 1 for computing weights by Fuzzy AHP since this technique uses only fuzzy inputs and not crisp numbers.

The sample involves 300 passengers belonging to different localities, age groups, professions, and gender. Out of the total sample, there were 200 male and 100 female respondents. Almost 23.4 percent of the respondents were aged between 30 and 50 years, while the majority of the commuters are in the age group of $<30$ years and constitute $76.6 \%$ of respondents. Table 1 illustrates the sample demographics statistics.

3.3. Phase 2: Factor Development. Based on their responses, the weights computed are provided as inputs to the ranking models TOPSIS/Fuzzy TOPSIS/EDA/IRP below. But before that, the next phase, phase 2 , involves classification of the factors into benefit and cost factors for inputting to the ranking models TOPSIS, Fuzzy TOPSIS, and EDA. For instance, political instability is considered a cost factor, implying that the higher the value, the more disruptive it is to the vehicle mode. At the same time, a positive sign $(+)$ is provided for fuel efficiency, which indicates that the higher the value, the more beneficial is the factor. The impacts of these criteria depicted in the criteria evaluation matrix were quantified on a 1-9 scale (Saaty scale) as follows: 1 (no effect) and 9 (highest impact), while for the alternatives, the rating score provided by the passengers was in a 1-10 scale as follows: 1 (lowest) and 10 (highest). Factors like fuel and | cost efficiency are measured per kilometer, while the operating cost is calculated on a monthly basis.

The issues were then categorized into factors and subfactors based on the PESTLE (Political, Economic, Social, Technological, Legal, Environmental) framework. The relative importance of the elements is computed by the Fuzzy AHP (Fuzzy Analytic Hierarchy Process). The best alternative mode of transport is assessed and ranked using the TOPSIS (Technique for Order of Preference by Similarity to Ideal Solution), Fuzzy TOPSIS, EDA, and IRP methods.

3.4. Phase 3: Weight Computation by Fuzzy-Analytical Hierarchy Process. The next phase, phase 3, involves computing the weights for each factor classified above using the Fuzzy Analytical Hierarchy Process (Fuzzy AHP). Before understanding the functionality of the Fuzzy AHP, the fuzzy set theory and the Analytical Hierarchy Process (AHP) are detailed below.

3.4.1. Fuzzy Set Theory. Any event, process, or function that is continuously variable and cannot be definitively categorized into true or false is said to be Fuzzy. Fuzzy logic implements the above principle to degrees of truth rather than the usual true/false or 1/0 like the Boolean logic. In
Table 1: Sample demographics.

\begin{tabular}{lcc}
\hline Gender & Number & Percentage \\
\hline Males & 200 & 66 \\
Females & 100 & 34 \\
Age & & \\
$<30$ years & 230 & 76.6 \\
30-50 years & 70 & 23.4 \\
Nature of locality & & \\
High class & 10 & 3.3 \\
Middle class & 220 & 73.3 \\
Lower middle class & 70 & 23.4 \\
Profession & & \\
Private employees & 120 & 40 \\
Government employees & 100 & 33.3 \\
Students & 50 & 16.6 \\
Miscellaneous & 30 & 10 \\
Total respondents & 300 & \\
\hline
\end{tabular}

fuzzy systems, the values are indicated between 0 (untrustworthy) to 1 (right).

Fuzzy Logic principles in set theory constitute Fuzzy Set Theory [46] that allows partial membership, i.e., contains the elements with variable membership in the set.

3.4.2. Analytical Hierarchy Process [47]. The Analytical Hierarchy Process (AHP) is a multicriterion approach adopted to assign relative weights to each criterion. AHP performs cost-benefit analysis based on absolute priorities $[48,49]$ and weightage ranking. The technique was devised by Wind and Saaty [50].

The AHP technique for computing the weights works as follows:

Step 1: the pairwise comparison criteria matrix $A$ is constructed in the form of a $x * x$ matrix, where $x$ is the number of factors considered in the study.

Each entry $a_{j k}$ of the matrix $A$ constitutes the relative weightage of the $j^{\text {th }}$ factor to the $k^{\text {th }}$ factor. If $a_{j k}>1$, the $j^{\text {th }}$ criterion is more critical, and if $a_{j k}<1$, the $j^{\text {th }}$ criterion is not considered as necessary as the $k^{\text {th }}$ criterion. If two criteria have the same level of importance, then the entry $a_{j k}$ is 1 .

The entries $a_{j k}$ and $a_{k j}$ satisfy the following constraint:

$$
a_{k j} * a_{j k}=1 \text {. }
$$

Obviously, $a_{j j}=1$ for all $j$.

The relative importance between the two criteria is quantified from 1 to 9 , as shown in Table 2:

The interpretations are reflective of the qualitative evaluations of how important a criterion is over the other.

Step 2: once the matrix $A$ is built, it is possible to derive from $A$ the normalized pairwise comparison matrix $A_{\text {norm }}$ where entry of the matrix $a_{j k \text { norm }}$ is:

$$
a_{j k \text { norm }}=\frac{a_{j k}}{\sum a_{l k}},
$$


TABLe 2: Fuzzy linguistic terms with defined triangular scales [50].

\begin{tabular}{lcc}
\hline Saaty scale & Definition & Fuzzy triangular scale \\
\hline 1 & Equally important & $(1,1,1)$ \\
3 & Weakly important & $(2,3,4)$ \\
5 & Fairly important & $(4,5,6)$ \\
7 & Strongly important & $(6,7,8)$ \\
9 & Absolutely important & $(9,9,9)$ \\
\hline
\end{tabular}

where $a_{l k}$ is the column-wise sum of entries for each criterion.

Step 3: finally, the factor weight vector $w_{j}$ is built by averaging the entries on each row of $A_{\text {norm }}$, i.e.,

$$
w_{j}=\frac{a_{j l \text { norm }}}{x} .
$$

Fuzzy Analytic Hierarchy Process (F-AHP) [51] integrates the fuzzy concept to Analytic Hierarchy Process (AHP). The pairwise comparisons are performed by representing linguistic variables as fuzzy triangular numbers.

The linguistic terms are defined in terms of the following sets of fuzzy triangular scales:

Table 2 depicts the Saaty scale from 1 to 9 and the corresponding fuzzy equivalent $(l, m, h)$; " $l$ represents the lower bound and " $h$ " the higher bound with the crisp score and the middle value by the variable " $m$." For instance, a Saaty scale value of 2 indicates the weak importance of factor " $i$ " while a value of 7 indicates high importance.

The weights computed by the Fuzzy AHP are validated by calculating two consistency ratios (CRm and CRg). These ratios are computed by the following procedure [52]:

Step 1: subdivide the fuzzy pair-wise comparison matrix (used for computing weights) into two matrices:

The first matrix is formed from the middle element " $m$ " of the fuzzy comparison matrix denoted by $A_{m}$ where: $A_{m}=\left[a_{i j m}\right]$.

The second matrix is derived as the geometric mean of the lower bound and the higher bound elements of the above fuzzy comparison matrix denoted by formula: $A_{g}=\left[a_{i j g}\right]$.

Step 2: the priority weight vector $W$ is computed as the normalized $n^{\text {th }}$ root of the elements in each of the above matrices:

where $n$ is the number of criteria considered in the study and $W_{i}=n^{\text {th }}$ is the root value of the criterion " $i$ " with respect to other criteria/sum of $n^{\text {th }}$ root values of all criteria

Step 3: the sum of product of all priority weight vector elements with their corresponding criteria columnwise sum computes the lambda-max for both the above matrices as follows:

where

$$
\begin{aligned}
& \text { lambda }-\max _{m}=\sum W_{i} * \text { row }- \text { wise sum of } a_{i j m}, \\
& \text { lambda }-\max _{g}=\sum W_{i} * \text { row }- \text { wise sum of } a_{i j g} .
\end{aligned}
$$

Step 4: compute the consistency index (CI) for each matrix from the corresponding lambda-max by the formulae:

$$
\mathrm{CI}_{m}=\frac{\left(\text { lambda }-\max _{m}-n-1\right)}{n},
$$

for the number of criteria " $n$ "

$$
\mathrm{CI}_{g}=\frac{\left(\text { lambda }-\max _{g}-n-1\right)}{n} \text {. }
$$

Step 5: compute the consistency ratio (CR) by dividing the Consistency index (CI) values by the Random Index (RI), where RI is specified by Gogus and Boucher [52] for each number of criteria(n), for instance, $\mathrm{RI}_{m}$ for the

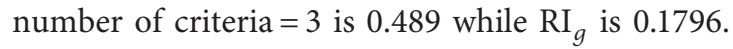

$$
\begin{aligned}
\mathrm{CR}_{m} & =\frac{\mathrm{CI}_{m}}{\mathrm{RI}_{m}}(n), \\
\mathrm{CR}_{g} & =\frac{\mathrm{CI}_{g}}{\mathrm{RI}_{g}}(n) .
\end{aligned}
$$

Step 6: check for $\mathrm{CR}_{m}$ and $\mathrm{CR}_{g}$ values; if they are less than $0.1(10 \%)$, they signify that the weights computed by Fuzzy AHP are valid, else the weights need to be checked.

3.5. Phase 4: Ranking the Viable Transport Alternatives. The vehicle transport alternatives are then ranked using the TOPSIS, Fuzzy TOPSIS, EDA, and IRP techniques detailed below:

3.5.1. Technique for Order of Preference by Similarity to Ideal Solution (TOPSIS) [42, 53]. TOPSIS is a multicriteria decision analysis method, which was originally developed by Hwang and Yoon [42]. The best option depends on the distance with respect to the average solution (AV).

The proposed technique works as follows:

Step 1: define the evaluation matrix consisting of $m$ alternatives and $n$ criteria as follows:

$$
X=\left[X_{i j}\right]_{n \times m}=\begin{array}{cccc}
X_{11} & X_{12} & & X_{1 m} \\
X_{21} & X_{22} & \ldots & X_{2 m}, \\
X_{n 1} & X_{n 2} & & X_{n m}
\end{array}
$$

where $X_{i j}$ denotes the decision value of the $i^{\text {th }}$ alternative on the $j^{\text {th }}$ criterion.

Step 2: the matrixes normalized to the matrix

$$
X_{\text {norm }}=\frac{X_{i j}}{\left(\sum x_{k j}^{2}\right)^{1 / 2}},
$$

where $i$ is from 1 to $m$ and $j$ is from 1 to $n$ using the normalization method 
Step 3: compute the weighted normalized decision matrix

$$
S_{i j}=X_{\text {norm }} * w_{j}
$$

Step 4: calculate the worst and best alternatives $A_{w}$ and $A_{b}$, respectively, as follows:

$$
\begin{aligned}
A_{b} & =\left[A_{b i j}\right]_{n \times m}, \\
A_{w} & =\left[A_{w i j}\right]_{n \times m} .
\end{aligned}
$$

if the $j^{\text {th }}$ criterion is beneficial,

$$
\begin{aligned}
& A_{b}=\operatorname{MAX}\left(X_{j}\right), \\
& A_{w}=\operatorname{MiN}\left(X_{j}\right) .
\end{aligned}
$$

if the $j^{\text {th }}$ criterion is nonbeneficial,

$$
\begin{aligned}
& A_{b}=\operatorname{MiN}\left(X_{j}\right), \\
& A_{w}=\operatorname{MAX}\left(X_{j}\right),
\end{aligned}
$$

where $A_{b i j}$ and $A_{w i j}$ represent the positive and negative proximity, respectively, from the average for a particular factor " $j$ "

Step 5: calculate the largest distance between the target alternatives $A$ and $A_{w}$ :

$$
d_{i w}=\left(\sum\left(A_{i j}-A_{w i j}\right)^{2}\right)
$$

$i$ is from $1,2,3,4, \ldots, m$

Similarly, compute the best distance between $A$ and $A_{b}$ :

$$
d_{i b}=\sum\left(A_{i j}-A_{b i j}\right)^{2}
$$

Step 6: calculate the similarity $s_{i w}$ :

$$
s_{i w}=\frac{d_{i w}}{\left(d_{i w}+d_{i b}\right)},
$$

where $s_{i w}$ ranges from 0 (worst) to 1 (best)

Step 7: the alternatives are ranked according to the $s_{i w}$.

The first ranked alternative is the best choice among the modes of transport.

3.5.2. Fuzzy TOPSIS [54]. Fuzzy TOPSIS is one of the best methods to get an ideal solution when there is uncertainty in the selection process. Fuzzy TOPSIS (F-TOPSIS) integrates the fuzzy concept to TOPSIS [55]. Fuzzy TOPSIS uses fuzzy triangular numbers in terms of the sets of fuzzy triangular scales defined in Table 2:

In the paper, the vehicle modes are ranked using Fuzzy TOPSIS technique in the $R$ tool, which has a predefined package "FuzzyMCDM" that considers the weights and input matrix for ranking the vehicles.
3.5.3. Evaluation Based on Distance from Average Solution (EDAS) [56]. This technique ranks the alternatives in terms of being the closest to the best-case and farthest from the worst-case scenario (nadir) solution [57]. The best option is a function of the distance from the average solution represented by AS. The ideal solution in the proposed method is not required to be computed. The Positive Distance and the Negative Distance from Average, i.e., PDA and NDA, are calculated. Let us suppose that we have $n$ alternatives and $m$ factors. The proposed technique works as follows:

Step 1: select the best factors defining the alternatives. Step 2: construct the alternative-criteria matrix $X$ :

$$
X=\left[X_{i j}\right]_{n \times m}=\begin{array}{cccc}
X_{11} & X_{12} & X_{1 m} \\
X_{21} & X_{22} & \ldots & X_{2 m}, \\
X_{n 1} & X_{n 2} & X_{n m}
\end{array}
$$

where $X_{i j}$ represents the $i^{\text {th }}$ alternative on the $j^{\text {th }}$ criterion.

Step 3: determine the mean solution AVshown as follows:

$$
A V=\left[A V_{j}\right]_{1 \times m}
$$

where

$$
A V_{j}=\frac{\sum X_{i j}}{N} .
$$

Step 4: the PDA and the NDA are computed differentially for cost and benefit criteria, shown as follows:

$$
\begin{aligned}
\mathrm{PDA} & =\left[\mathrm{PDA}_{i j}\right]_{n \times m}, \\
\mathrm{NDA} & =\left[\mathrm{NDA}_{i j}\right]_{n \times m} .
\end{aligned}
$$

, if the $j^{\text {th }}$ criterion is beneficial,

$$
\begin{aligned}
\operatorname{PDA}_{i j} & =\frac{\operatorname{MAX}\left(0, X_{j}-A V_{j}\right)}{A V_{j}}, \\
\mathrm{NDA}_{i j} & =\frac{\operatorname{MAX}\left(0, A V_{j}-X_{j}\right)}{A V_{j}} .
\end{aligned}
$$

if the $j^{\text {th }}$ criterion is nonbeneficial,

$$
\begin{aligned}
\operatorname{PDA}_{i j} & =\frac{\operatorname{MAX}\left(0, A V_{j}-X_{j}\right)}{A V_{j}}, \\
\mathrm{NDA}_{i j} & =\frac{\operatorname{MAX}\left(0, X_{j}-A V_{j}\right)}{A V_{j}},
\end{aligned}
$$

where $\mathrm{PDA}_{i j}$ and $\mathrm{NDA}_{i j}$ denote the positive and negative distance, respectively, from the average solution for a particular factor $j$.

Step 5: compute $\mathrm{SP}_{i}$ and $\mathrm{SN}_{i}$ for all alternatives, shown as follows: 


$$
\begin{aligned}
\mathrm{SP}_{i} & =\sum w_{i} * \mathrm{PDA}_{i j} \\
\mathrm{SN}_{i} & =\sum w_{i} * \mathrm{NDA}_{i j}
\end{aligned}
$$

where $w_{i}$ is the weight of the $i^{\text {th }}$ criterion.

Step 6: compute the normalized values of SP and SN for all alternatives, shown as follows:

$$
\begin{aligned}
\mathrm{NSP}_{i} & =\frac{\mathrm{SP}_{i}}{\max \left(\mathrm{SP}_{i}\right)}, \\
\mathrm{NSN}_{i} & =\frac{\mathrm{SN}_{i}}{\max \left(\mathrm{SN}_{i}\right)} .
\end{aligned}
$$

Step 7: evaluate AS for all electives, shown as follows:

$$
\mathrm{AS}=0.5 *\left(\mathrm{NSN}_{i}+\mathrm{NSP}_{i}\right) \text {. }
$$

Step 8: the alternatives are ranked in the descending order of the average score, AS, and the highest average score is considered the best alternative.

3.5.4. Interpretive Ranking Procedure (IRP) [58]. The IRP is a ranking procedure used for validation and is adopted due to the perfect blending of rational selection processes with rudimentary intuitive processes.

The IRP is a novel ranking method [59] that ranks individual actors based on their performance outcomes viz-aviz internal and external processes.

In the IRP, expert inputs that impact the interpretive logic for factor dominance are applied for paired comparison. The IRP makes it easy to distinguish the influence of interactions rather than the variables in an abstract sense.

The basic steps of the IRP are as follows:

(1) Categorize the variables into two sets-one to be ranked, second the criteria for ranking

(2) Identify the relationship between the two sets of variables

(3) Construct a cross-interaction matrix between the two sets of variables
(4) Interpret the binary relationships by converting to a cross-interpretive matrix

(5) Translate the matrix into a dominating interactions matrix representing the relative dominance of one actor over the other

(6) Rank the actors or alternatives based on the net dominant score

3.6. Phase 5: Validation of the Rankings. The final phase is the validation of the rankings for which the Ensemble Ranking procedure is adopted. The Ensemble Ranking technique is constructed from the above four methods (TOPSIS, Fuzzy TOPSIS, EDA, and IRP) using the methodology entailed in Mohammadi and Rezaei [43]. The weights computed above are also validated by domain experts in the field of transportation.

The methodology aims to compute a consolidated ranking system from different individual ranking systems to maximize the rankings' consensus and validity.

Consider " $n$ " techniques which assign a rank of $R_{1}, R_{2}$, $R_{3}, \ldots, R_{\mathrm{n}}$ to a particular alternative based on their respective methodology. Consider an assumed consolidated ranking of $R^{*}$ for the alternative. The Ensemble Ranking technique aims to minimize each rank's Euclidean distance from the above consolidated ranking $R^{*}$.

For this purpose, a quadratic minimizer function is constructed as

$$
\min \frac{1}{2} * \sum_{n=1}^{N}\left(R_{n}-R^{*}\right)^{2}
$$

where $R_{n}$ is the individual computed rank, and $R^{*}$ is the consolidated assumed ranking. The above function aims to maximize the consensus to consolidated ranking by minimizing the distance to the consolidated ranking.

An optimal weighted Ensemble ranking procedure is formulated by assigning individual weights $w_{1}, w_{2}, \ldots, w_{n}$ to each of the procedures and changing the weights iteratively till a convergence to the final solution is reached.

Each auxiliary variable representing each individual ranking method is denoted by $\alpha$; where

$$
\alpha 1=\mu *\left(R 1-R^{*}\right)^{2} \text { [representing minimize function for rank method 1]. }
$$

The weights are computed as the normalized form of auxiliary variables by the formula:

$$
w_{n}=\frac{\alpha_{n}}{\sum_{1}^{N} \alpha_{n}} .
$$

The consolidated ranking is the sum-product of each rank with respective weightage:

$$
R^{*}(\text { optimal })=\sum_{n} w_{n} R_{n}
$$

Figure 3 summarizes the methodology adopted by this study below:

The results are enclosed in Section 5. The proposed multicriteria model explaining the relationship between the criteria and the alternatives based on the nature of vehicle is illustrated below:

\section{Proposed PESTLE Model}

The model determines the best vehicle mode constructed based on a tree structure with level 1 (top-most root) as the 


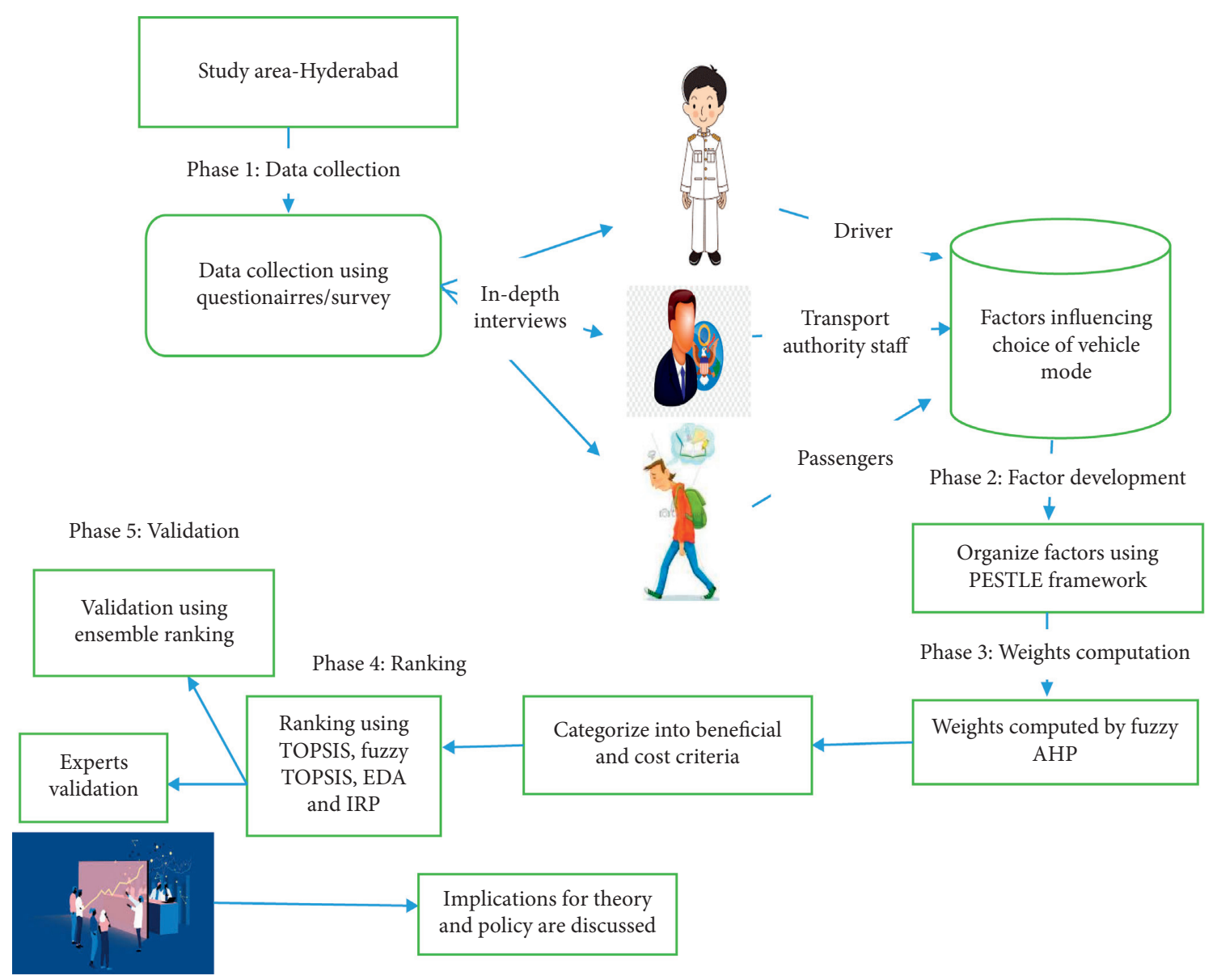

Figure 3: Methodology adopted for the study.

multicriteria objective of choosing the most feasible and viable transport mode alternative for passengers. Secondly, the vehicle alternatives are specified in level 2 , and criteria in level 3.

Figure 4 illustrates the proposed hybrid model to examine the criteria for choosing a vehicle mode for the passengers among alternative options (defined in Level $1)$. The criteria considered are: Political, Economic, Social, Technological, Legal, and Environmental factors (subfactors are illustrated in Figure 1). These are the criteria that the passenger considers for choosing the best vehicle alternative. The Fuzzy AHP is initially used (placed at Level 3) to separately perform pair-wise comparisons for factors and the alternatives, and to compute the fuzzy weights or priorities assigned to the criteria. Furthermore, the criteria are grouped into beneficial and nonbeneficial criteria, and these are applied on four vehicle modes, namely, Metro, Car, Public bus, and bike. The four vehicle alternatives are then ranked according to three methods: TOPSIS, Fuzzy TOPSIS, EDA, and the IRP techniques and compared (shown in Level 2). They are then validated by the Ensemble Ranking technique. The next section discusses the application of the proposed model in the context of this paper.

\section{Application of the Proposed Model and Results}

5.1. Study Area and Scope. Hyderabad, the capital of Telangana, the newly formed 29th state of India, has been selected as a case in point for metropolitan cities. The population is 13 million, of which around $13 \%$ are below the poverty line and earn an income of Rs. 4 Lakh per capita [60]. The population density is reported to be 18,480 per sq.km. The city generates around 45,000 motorized vehicle trips per day [61].

The suitability of the vehicle modes is not evaluated in terms of absolute importance. They are evaluated from the point of view of relative applicability in Hyderabad.

This study was conducted on the busy route connecting Nagole, an eastern residential suburb in the city outskirts of Hyderabad, to the other end of the city, Hitech City, the financial and technological hub employing millions of software professionals and analysts. Figure 5 illustrates the map of Hyderabad and a picture illustrating the routes.

This study considers four modes of transportation, locally known as-Metro train, Public bus, Bike, and Car as alternatives. Bike is a two-wheeler micro-mobility vehicle mode controlled by a handlebar. Rickshaws constitute $30 \%$ of the terrestrial vehicles and $23 \%$ of commuters with an 


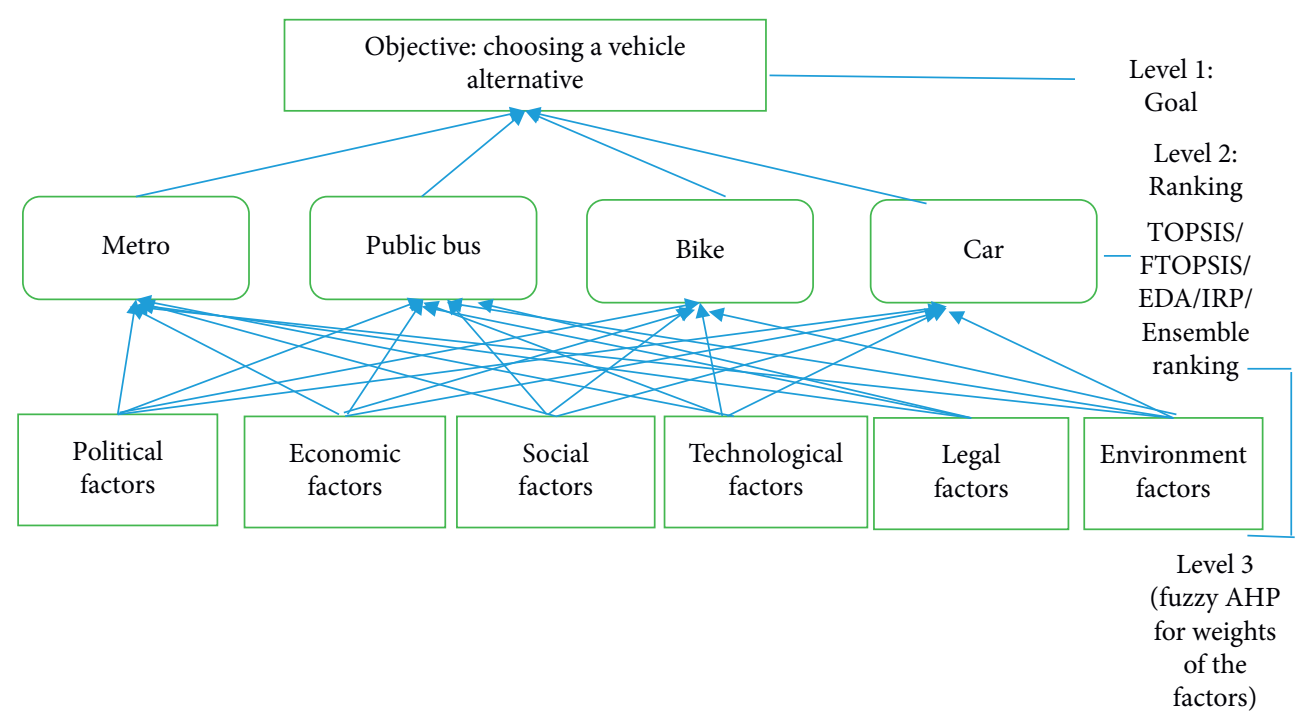

FIgURE 4: The proposed model.

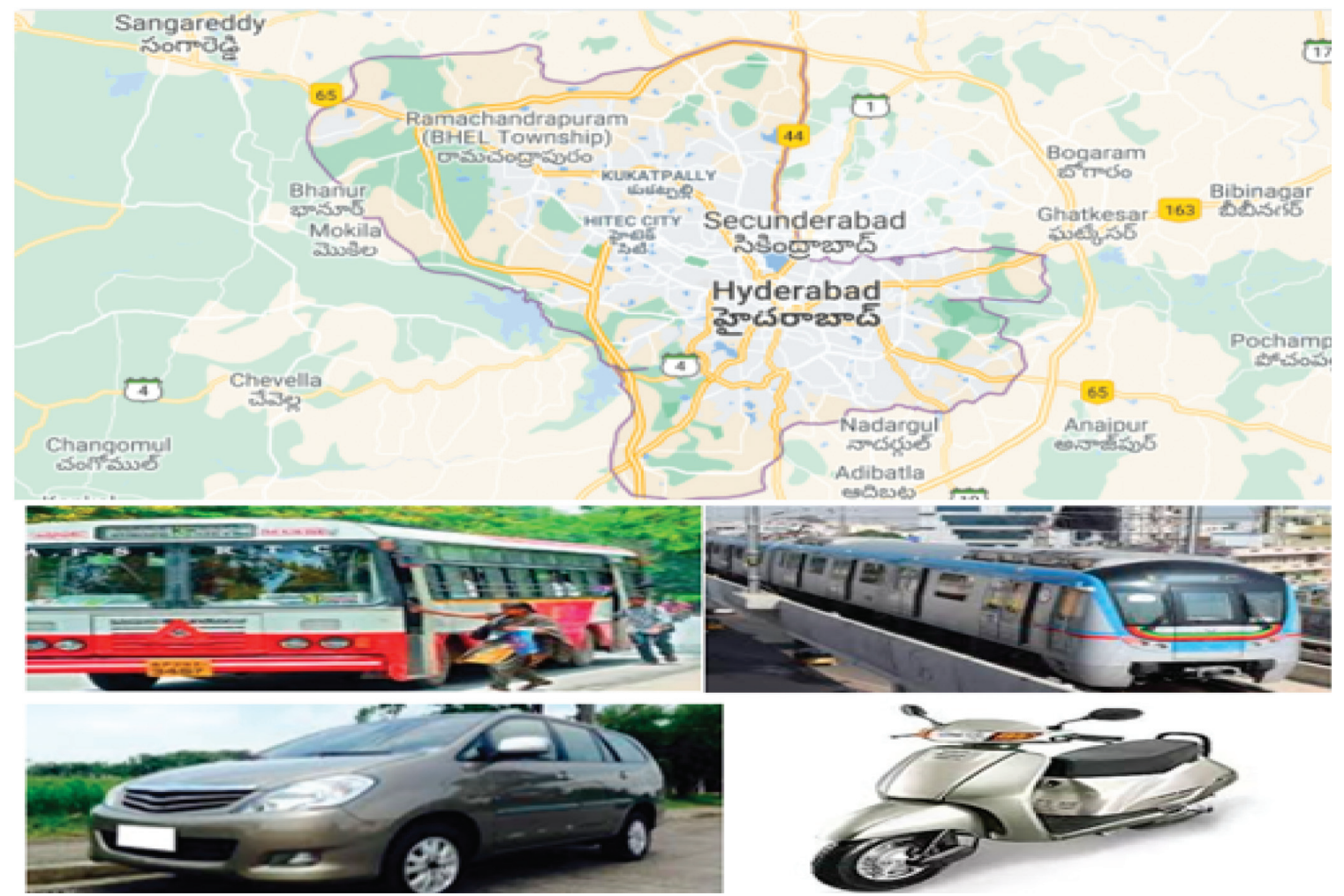

FIgURE 5: The modes of transport, their routes, and the study area (in clockwise order, public bus, metro train, bike, and car).

average trip length of $8.76 \mathrm{~km} \mathrm{[62].} \mathrm{A} \mathrm{bus} \mathrm{is} \mathrm{a} \mathrm{four-wheeled}$ vehicle carrying passengers by road on a fixed route and driven by a bus driver. Bus comprises almost $70 \%$ of the road transport [63] and is currently an accessible and frequent transportation mode for commuting within the city and is routed throughout the city radius. A car comprises about $20-30 \%$ of the road transport and is a less economical means of transportation. A metro train is a transit train that is customized for metropolitan cities. It is currently new to the city of Hyderabad. It has a daily occupancy of 4.62 lakh passengers [64] and covers the $30-\mathrm{km}$ stretch from Hitech City to Nagole (the route considered for the study). A snapshot of the route and the vehicles discussed above is illustrated in Figure 5:

The phases illustrated above in Methodology are implemented below for the scenario: 
5.2. Computing Weights Using Fuzzy AHP [65]. The criteria are defined and the pair wise matrix is evaluated with relative weightages assigned to each ordered tuple of criteria $\left(C_{i}, C_{j}\right)$, where $i<j$ for all 6 factors defined above in the PESTLE framework: Political, Economic, Social, Technological, Legislative and Environmental factors subdivided into the 13 subcriteria: Political Stability, Government Policy, Duties and Taxes, Economic Growth, Unemployment, Cost Efficiency, Health, Safety, Security, Maintenance, Fuel Efficiency, Restricted Movement, and Pollution. This helps in evaluating the relative criteria significance.

The weights of all criteria computed by Fuzzy AHP is illustrated in Table 3, where the Fuzzy set weights $\mathrm{Si}$, the crisp weightages, and the relative normalized weights of the factors are depicted.

Table 3 illustrates the normalized weights for each of the factors computed from the Fuzzy AHP. It is found that Political factors are the most important, followed by Social factors and Technological factors and then Economic Factors. This is because for the practical implementation of a new transport mode (in this case, metro), the political clearances are initially sought, followed by examining the impact of the new transport mode on society. Subsequently, the technological know-how is sought to construct the infrastructure while taking care of the economic and environmental factors.

The weights computed above are validated for consistency by computing the consistency ratios as elucidated above in methodology Section 3.4.2, and the values of lambda- $\max _{\mathrm{m}}$ and lambda- $\max _{\mathrm{g}}$ are first computed as: lambda- $\max _{m}=6.22$ and lambda $-\max _{g}=6.11$.

Furthermore, the consistency index values are: $\mathrm{CI}_{m}=0.044$ and $\mathrm{CI}_{g}=0.022$.

Furthermore, for the number of criteria $=6$ (in study), the corresponding Random index (RI) values according to Gogus and Boucher [52] were specified to be $\mathrm{RI}_{m}=1.19$ and $\mathrm{RI}_{g}=0.38$.

Therefore, the consistency ratio values $\mathrm{CR}_{m}$ and $\mathrm{CR}_{g}=\mathrm{CR}_{m}=\mathrm{CI}_{m} / \mathrm{RI}_{m}=0.044 / 1.19=0.0368$ $\mathrm{CR}_{g}=\mathrm{CI}_{g} / \mathrm{RI}_{g}=0.022 / 0.38=0.0578(5.8 \%)$

Both ratios are less than $0.1(10 \%)$, which implies that the weights computed by the above Fuzzy AHP procedure are valid.

Furthermore, to analyze the subcriteria weights, the pairwise comparison matrices for all the subfactors were similarly constructed to calculate their relative contribution toward the main factors.

Table 4 presents the results of the relative weights of all the subfactors.

It is found that Political Instability (Political Factor) is the major barrier followed by Safety (Social Factor), Government policies (Political Factor), and Fuel efficiency (Technological Factor). This corroborates the above findings in Table 4, indicating that Political Instability, which quantifies the authority of the political party, is most essential for the successful implementation of a new transport mode followed by social factors like safety, government policies, and technological factors like fuel efficiency.
5.3. Ranking of the Vehicle Modes. First, the weights are provided as input to the TOPSIS model after categorization into beneficial and nonbeneficial subcriteria. For instance, the subcriteria Political Instability, Government Policies, and Pollution are nonbeneficial and are considered as negative drivers for choosing the vehicle alternative while Fuel Efficiency, Cost Efficiency, and Employment are positive drivers or beneficial factors. Subsequently, the Positive and Negative Distance from the ideal solutions, i.e., the PIS and the NIS, were calculated through the weighted normalized decision matrix. As these ideal solutions represent the hypothetical scenario, the distance of each alternative from these extremes was calculated ( $\mathrm{Di}+$ and $\mathrm{Di}-$ ). Based on these distances, the relative closeness index, $\mathrm{Ci}$, was computed to rank these alternatives using TOPSIS in Table 5 finally.

Similarly, the weighted criteria and alternative evaluation matrix are input in $R$ for computing the rank using Fuzzy TOPSIS, and the results are illustrated in Tables 6 and 7:

The evaluation matrix above represents the weights assigned to the criteria and the alternative scores (out of 10) assigned for each of the alternative transport modes; for instance, Metro is assigned a score of 10 for Technological Factors. In contrast, the Public bus is assigned a score of 7 , Bike a score of 5 , and Car a score of 8 .

The above responses average the rating provided to the subcriteria under each of the criteria based on questions asked to the passengers (questionnaire of interview enclosed in Appendix). For instance, the above response 10 for Political Factors is the aggregated average of the rating provided to each of the Political Factors, i.e., Political instability and Government Policies (out of 10) by the passengers. The aggregated Evaluation Matrix in Table 6 for the factors is thus represented for the sake of brevity.

The same evaluation matrix in Table 6 is used as the input to the EDA model, and the PDA and the NDA were computed. Then, the weighted sum product of the PDA and the NDA, namely, SPi and SNi, respectively, were calculated for all the alternatives. After normalizing the weighted scores to $\mathrm{NSP}_{i}$ and $\mathrm{NSN}_{i}$, the final appraisal score $\left(\mathrm{AS}_{i}\right)$ was calculated to rank the alternatives in Table 8:

The Interpretative Ranking Procedure (IRP) is implemented based on the SAP-LAP framework (Situation-ActorProcesses- Learning- Actions-Performance) where the above vehicle alternatives are considered as actors that are mapped to processes as shown in the framework in Table 9:

The SAP-LAP framework in Table 9 highlights the Situations, Actors, and Processes involved in this paper. The Situations are classified into external and internal situations, namely S1, which represents the growth of unconventional transportation modes in India metro cities, and S2, which is characterized by strong technological developments. Actors are the different external alternatives defined as A1 (Car), A2 (Bike), A3 (Metro), and A4 (Public bus). Processes are internal (P1- Technology and Business Strategy Alignment) and external (P2-Offering feasible transport alternative to commuters). 
TABle 3: Weights computed from the fuzzy AHP.

\begin{tabular}{lccc}
\hline Criteria & Fuzzy set $(\mathrm{Si})$ & Weightages & Normalized weights \\
\hline Political factors & $(0.198,0.329,0.523)$ & 0.349 & 0.388 \\
Economic factors & $(0.065,0.102,0.162)$ & 0.121 & 0.121 \\
Social factors & $(0.111,0.192,0.323)$ & 0.209 & 0.231 \\
Technological factors & $(0.070,0.111,0.181)$ & 0.110 & 0.134 \\
Legal factors & $(0.033,0.049,0.081)$ & 0.054 & 0.059 \\
Environmental factors & $(0.035,0.053,0.091)$ & 0.059 & 0.066 \\
\hline
\end{tabular}

TABLE 4: Relative weights of the subfactors.

\begin{tabular}{lcc}
\hline Criteria & Subcriteria & Weights of subcriteria \\
\hline Political factors & Political instability & 0.187 \\
& Government policies & 0.101 \\
& Duties and taxes & 0.032 \\
Economic factors & Economic growth & 0.034 \\
& Employment & 0.049 \\
& Cost efficiency & 0.082 \\
Social factors & Health & 0.052 \\
& Safety & 0.104 \\
Technological factors & Security & 0.078 \\
& Maintenance & 0.079 \\
Legal factors & Fuel efficiency & 0.090 \\
& Restricted movement & 0.035 \\
Environmental factors & Legislations & 0.034 \\
\end{tabular}

TABLE 5: TOPSIS results for the respondents.

\begin{tabular}{lcccc}
\hline Alternative mode & $\mathrm{Di}^{+}$ & $\mathrm{Di}^{-}$ & $\mathrm{Ci}$ & \\
\hline Metro & 0.089 & 0.228 & 0.718 & \\
Public bus & 0.197 & 0.095 & 0.325 & 2 \\
Bike & 0.226 & 0.101 & 0.309 & 3 \\
Car & 0.225 & 0.096 & 0.299 & 4 \\
\hline
\end{tabular}

TABLe 6: Criterion- alternative evaluation matrix.

\begin{tabular}{|c|c|c|c|c|c|c|}
\hline $\begin{array}{l}\text { Weights } \\
\text { Alternative mode }\end{array}$ & $\begin{array}{c}0.388 \\
\text { Political factors }\end{array}$ & $\begin{array}{c}0.121 \\
\text { Economic factors }\end{array}$ & $\begin{array}{c}0.231 \\
\text { Social factors }\end{array}$ & $\begin{array}{c}0.134 \\
\text { Technological factors }\end{array}$ & $\begin{array}{c}0.060 \\
\text { Legal factors }\end{array}$ & $\begin{array}{c}0.066 \\
\text { Environmental factors }\end{array}$ \\
\hline Metro & 4 & 6 & 9 & 10 & 9 & 9 \\
\hline Public bus & 8 & 6 & 8 & 7 & 10 & 10 \\
\hline Bike & 7 & 9 & 10 & 5 & 7 & 7 \\
\hline Car & 8 & 5 & 7 & 8 & 5 & 5 \\
\hline
\end{tabular}

TABle 7: Fuzzy TOPSIS results for the respondents.

\begin{tabular}{lc}
\hline Alternative mode & Rank \\
\hline Metro & 1 \\
Public bus & 2 \\
Bike & 4 \\
Car & 3 \\
\hline
\end{tabular}

The dominance matrix in Table 10 is constructed by counting the row-wise and column-wise occurrences, indicating the number dominating $(D)$. The number dominated $(B)$ and the net dominance calculated by the difference between $D$ and $B$ determines the final ranking.
TABLE 8: EDA results.

\begin{tabular}{lcccccc}
\hline $\begin{array}{l}\text { Alternative } \\
\text { mode }\end{array}$ & $\mathrm{SP}_{i}$ & $\mathrm{NSP}_{i}$ & $\mathrm{SN}_{i}$ & $\mathrm{NSN}_{i}$ & $\mathrm{AS}_{i}$ & Rank \\
\hline Metro & 0.08985 & 0.23505 & 0.52052 & 0.71514 & 0.61783 & 1 \\
Public bus & 0.17261 & 0.04153 & 1 & 0.12635 & 0.56317 & 2 \\
Bike & 0.16389 & 0.02335 & 0.94948 & 0.07105 & 0.51027 & 4 \\
Car & 0.01734 & 0.32868 & 0.10044 & 1 & 0.55022 & 3 \\
\hline
\end{tabular}

The overall ranking of the vehicle alternatives under TOPSIS, Fuzzy TOPSIS, EDA, and IRP is summarized in Table 11: 
TABLE 9: Variables of SAP-LAP in the context of choosing a suitable vehicle mode.

\begin{tabular}{lcc}
\hline Components & & Variables \\
\hline Situation & External & S1- growth of unconventional transportation modes \\
& Internal & S2- strong technological developments \\
& & A1-car \\
Actors & External & A2-bike \\
& & A3-metro \\
& Internal & A4-public bus \\
Processes & External & P1- technology and business strategy alignment \\
& & P2-offering feasible transport alternative to commuters \\
\hline
\end{tabular}

TABLE 10: Dominant matrix of actors with respect to processes.

\begin{tabular}{|c|c|c|c|c|c|c|c|}
\hline & A1 & A2 & A3 & A4 & No. dominating $(D)$ & $D-B$ & Rank \\
\hline $\mathrm{A} 1$ & & 1 & & & 1 & 0 & 3 \\
\hline $\mathrm{A} 2$ & & & & & 0 & -3 & 4 \\
\hline A3 & 1 & 1 & 1 & & 3 & 2 & 1 \\
\hline A4 & & 1 & & & 1 & 1 & 2 \\
\hline No. being dominated $(B)$ & 1 & 3 & 1 & 0 & 5 & & \\
\hline
\end{tabular}

TABle 11: Comparison of ranking from different techniques.

\begin{tabular}{lcccc}
\hline Alternative & EDA & TOPSIS & Fuzzy-TOPSIS & \\
\hline Metro & 1 & 1 & 1 & IRP \\
Public bus & 2 & 2 & 2 & 2 \\
Bike & 4 & 3 & 4 & 4 \\
Car & 3 & 4 & 3 & 3 \\
\hline
\end{tabular}

The Metro and Public bus alternatives are consistently found to be the top 2 recommended vehicle modes under all the four techniques (EDA, TOPSIS, Fuzzy TOPSIS, and IRP), the Car is found to be the next preferred alternative under EDA and Fuzzy TOPSIS, and the TOPSIS method is found to rank the Bike as the next preferred alternative.

A sensitivity analysis of the models is performed below:

5.4. Sensitivity Analysis. The sensitivity analysis is used to investigate the results' stability over a varied range of input variable values. There are 13 subfactors involved in the current study, but the analysis of over 13 weight patterns became cumbersome. Therefore, to better understand the results, the top 5 subfactors were selected for the final analysis based on their relative importance. The factors chosen for the study are Political Instability, Cost Efficiency, Safety, Government policies, and Fuel Efficiency. The results' stability is analyzed by testing the model over five different sets of weights (indicated by P1-P5) of the top 5 subcriteria. The weights of the subcriteria computed in Table 4 were varied with 5 different combinations, and the impact on the vehicle mode ranking was empirically observed from the combinations. Table 12 demonstrates the weights considered for the subcriteria.

The sensitivity analysis charts are plotted for each of the individual multicriteria methods, namely, TOPSIS, Fuzzy TOPSIS, EDA, and IRP. The vertical bars are colored blue for the metro, orange for the public bus, gray for the bike, and yellow for the car. The bars' size is inversely proportional to ranking (longer the bar, lower it is in terms of alternative ranking).

In TOPSIS, the Metro as an alternative is found to be consistently in the top 2 alternatives, the Car is found to be consistently in the 3rd or 4th position, and the rankings of Public bus and Bike are found to be less stable.

In the Fuzzy TOPSIS, Metro is again found to be stable in the top two while the other modes of transport are varying and fluctuating.

In EDA, the Metro is the most consistently superior alternative, while the next stable choice is the Bike. The ranking of the Public bus and the Car are highly unstable; similar is the case for the IRP process.

Overall, from the sensitivity analysis depicted in Figures 6-9, the Metro is found to be the most feasible alternative, while the other options differ based on the weight assigned; for instance, if Safety and Fuel Efficiency is given high weightage, the Car is preferred. In contrast, if Cost Efficiency is given priority, the Public bus is preferred as a cheaper alternative with high connectivity.

5.5. Validation of Rankings Using Ensemble Ranking. Furthermore, the above rankings are validated by the Ensemble Ranking technique, which assigns weights to each of the ranking algorithms, namely, TOPSIS, Fuzzy TOPSIS, EDA, and IRP to compute a consolidated ranking system for the tables. 
TABLE 12: Sets of weights used for sensitivity analysis.

\begin{tabular}{lccccc}
\hline Weights & Political instability & Cost efficiency & Safety & Government policies & Fuel efficiency \\
\hline P1 & 0.187 & 0.110 & 0.104 & 0.101 & 0.091 \\
P2 & 0.172 & 0.156 & 0.103 & 0.089 & 0.095 \\
P3 & 0.155 & 0.134 & 0.091 & 0.137 & 0.117 \\
P4 & 0.194 & 0.121 & 0.106 & 0.095 & 0.105 \\
P5 & 0.191 & 0.109 & 0.117 & 0.114 \\
\hline
\end{tabular}

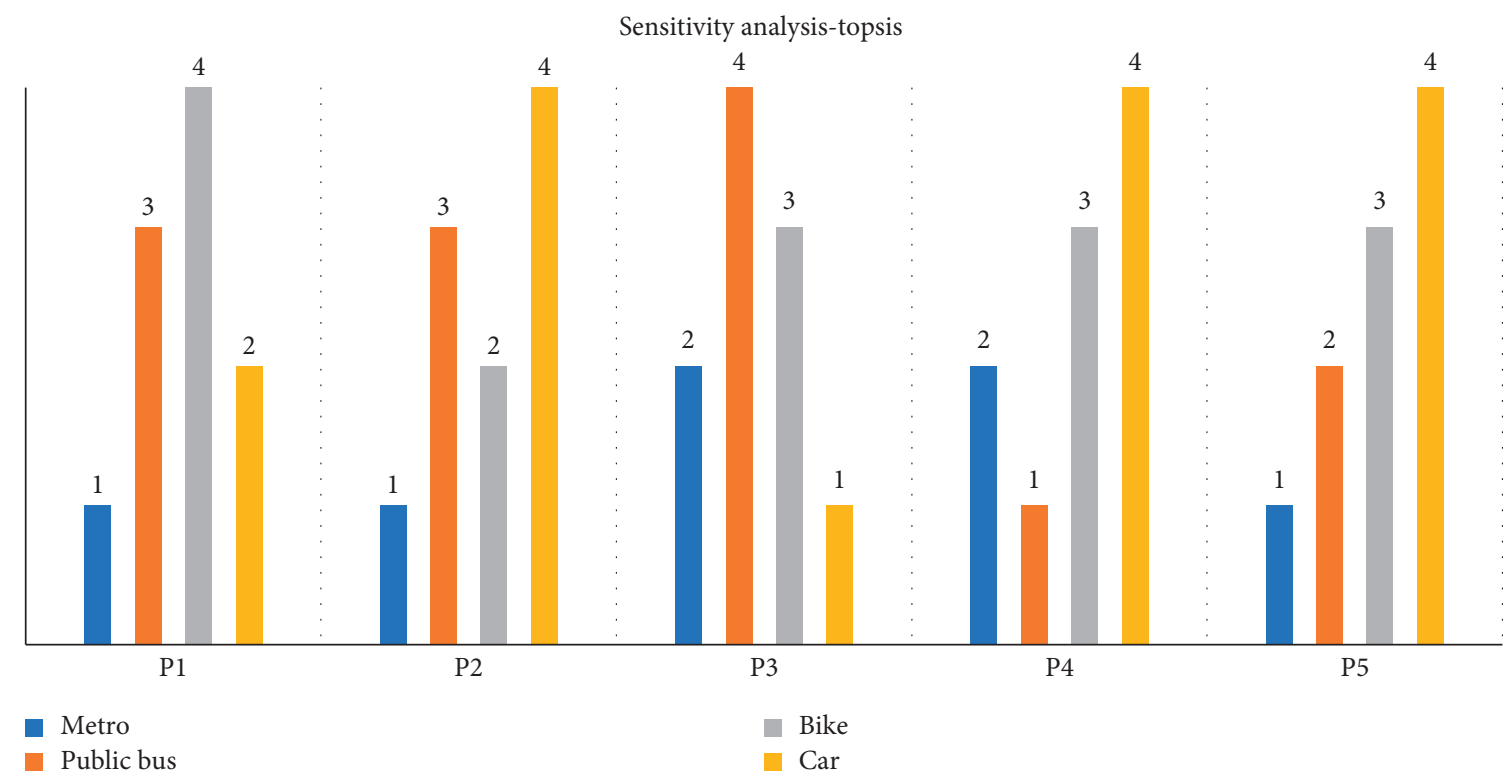

Figure 6: Sensitivity analysis using TOPSIS.

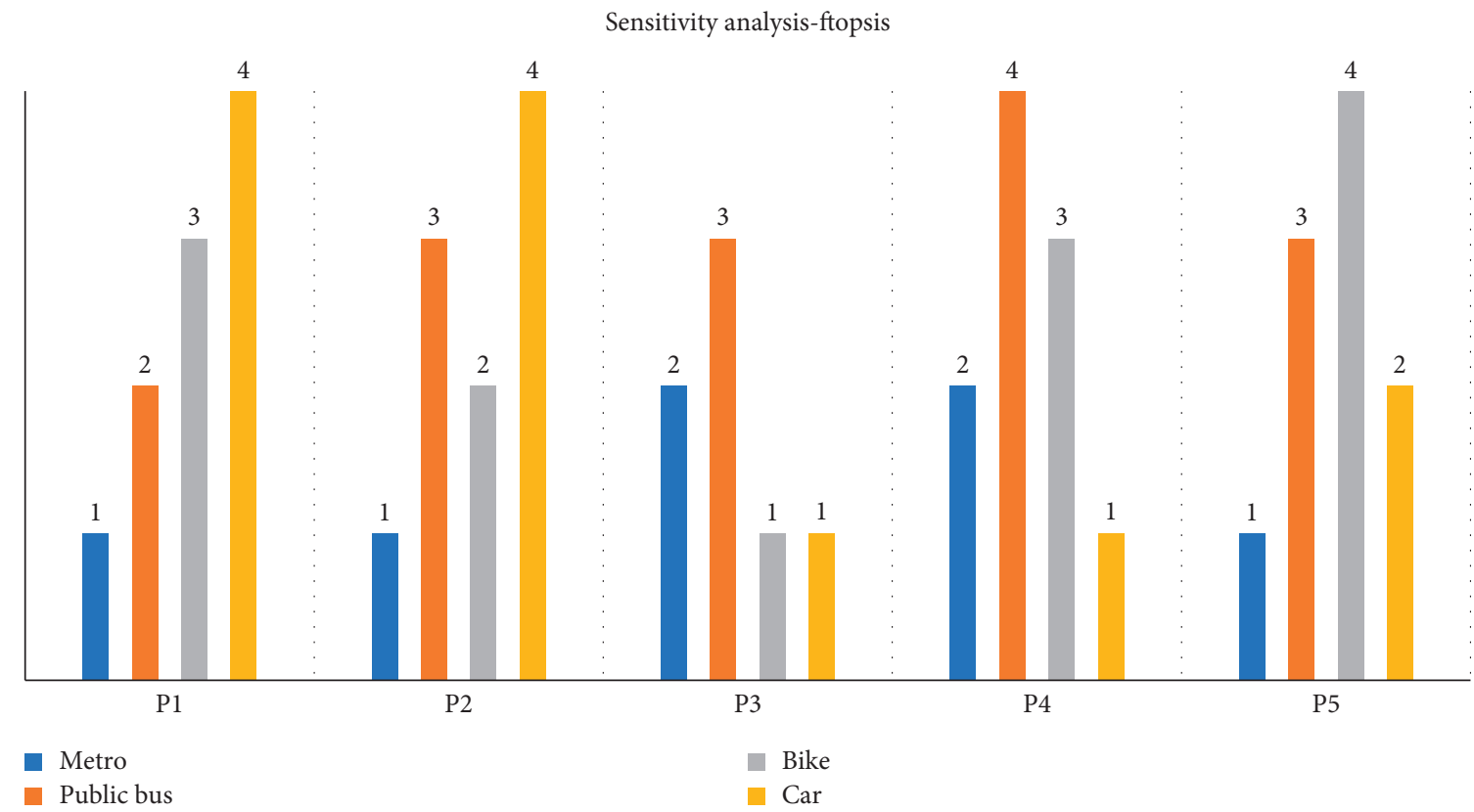

FIgURE 7: Sensitivity analysis using Fuzzy TOPSIS. 


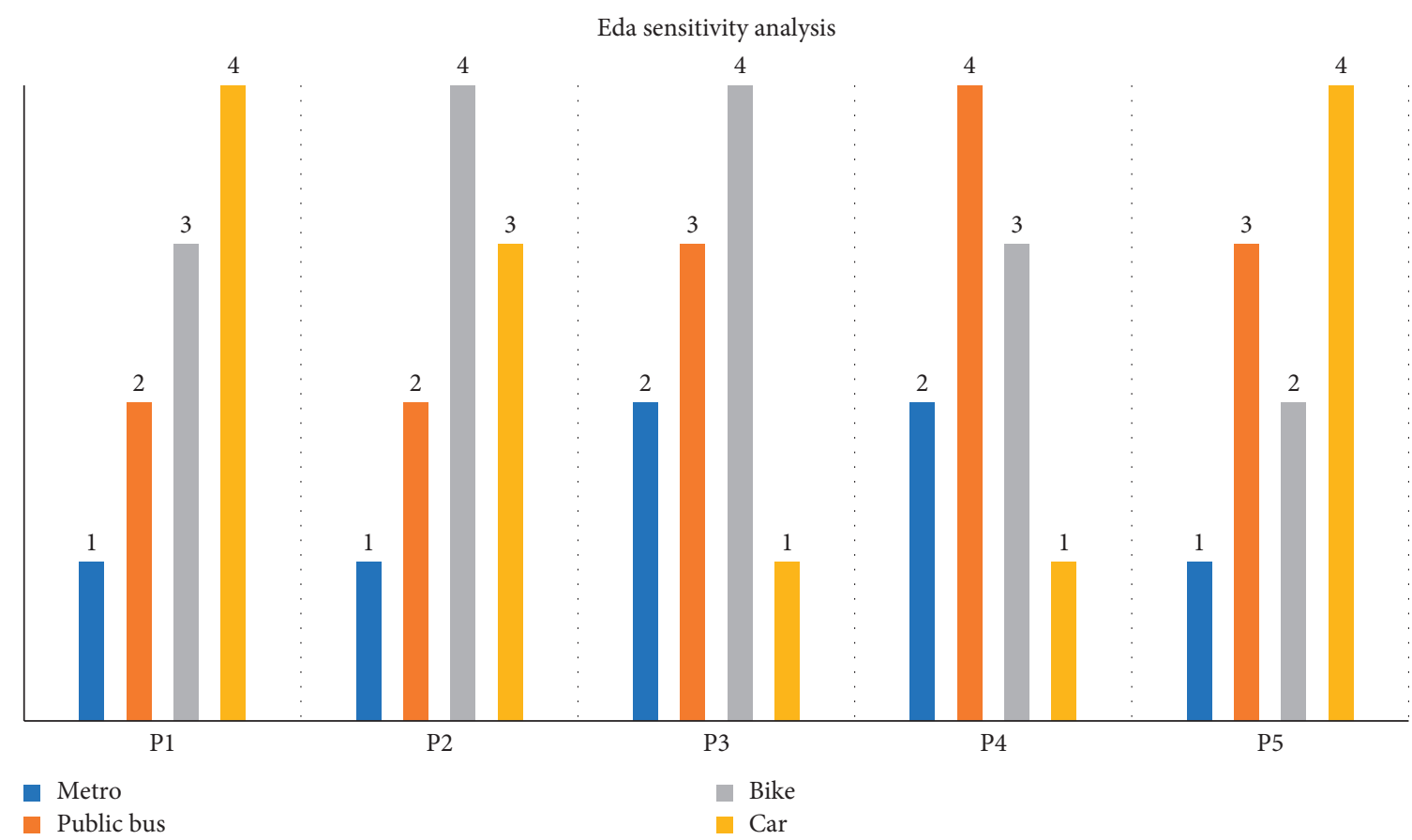

Figure 8: Sensitivity analysis using EDA.

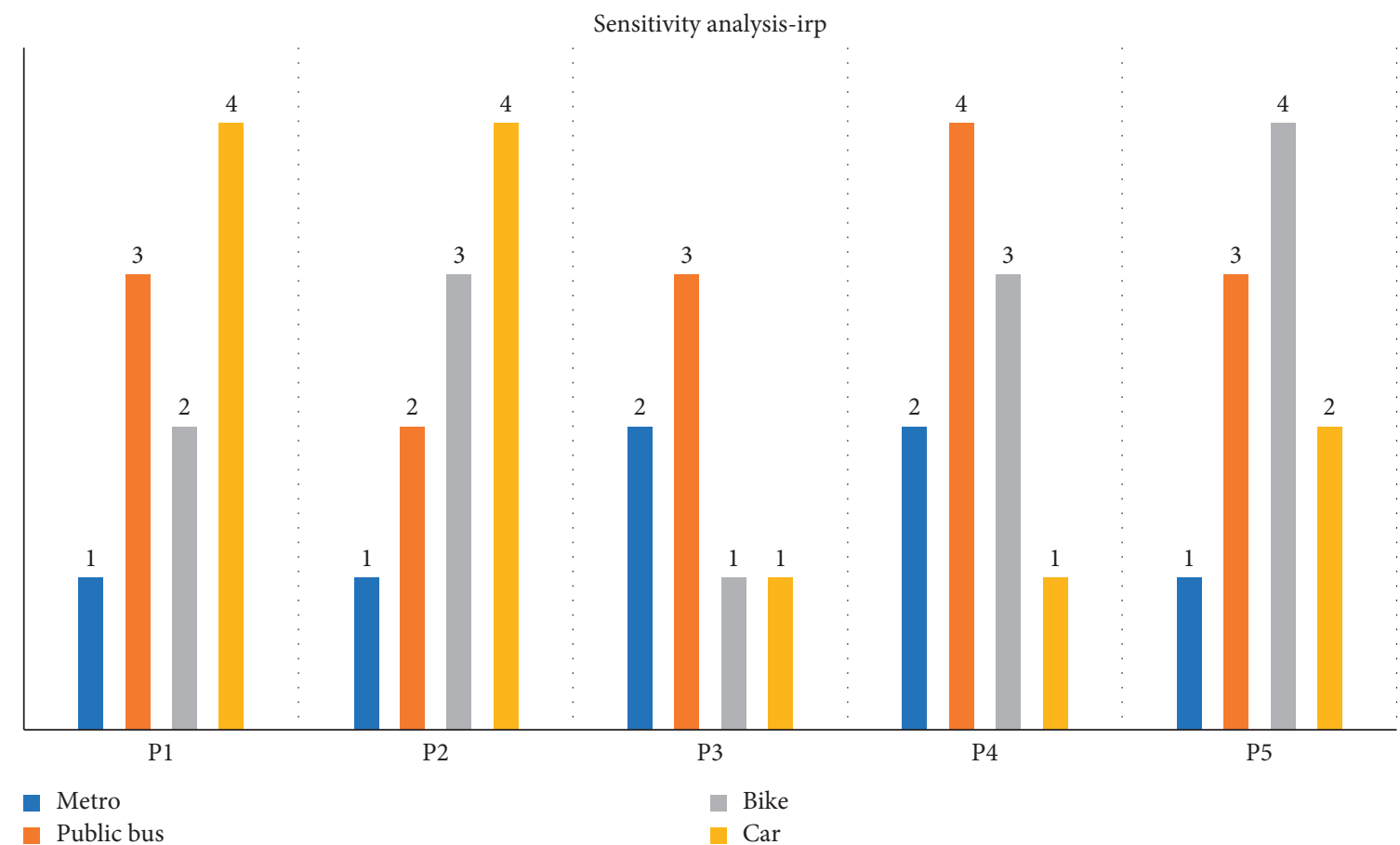

FIGURE 9: Sensitivity analysis using IRP.

The weights for each of the ranking algorithms are optimized using an inbuilt solver function, and the results of the Ensemble Ranking are illustrated in Table 13:

The weightages for each ranking system are optimized by an inbuilt Excel macro solver, which on clicking a button, automatically (through its inbuilt macro solver code) assigns optimal weights to each ranking algorithm ensuring that the confidence index and trust level of the algorithms are maximized [43]. EDA and Fuzzy TOPSIS are both assigned the highest weightage by the solver (33.33\%), and the IRP is assigned a weightage of $27.1 \%$.

The confidence index is a measure of extent to which all the four models, namely, TOPSIS, Fuzzy TOPSIS, EDA and IRP, are in concordance with the aggregate ranking $R^{*}$. In 
TABLE 13: Ensemble ranking technique results.

\begin{tabular}{|c|c|c|c|c|c|c|}
\hline Alternative & EDA & TOPSIS & Fuzzy-TOPSIS & IRP & $R^{*}$ & Final rank \\
\hline Metro & 1 & 1 & 1 & 1 & 1 & 1 \\
\hline Public bus & 2 & 2 & 2 & 2 & 2 & 2 \\
\hline Bike & 4 & 3 & 4 & 4 & 4 & 4 \\
\hline Car & 3 & 4 & 3 & 3 & 3 & 3 \\
\hline Weights computed & 0.33 & 0.069 & 0.33 & 0.271 & $\begin{array}{c}\text { Confidence index } \\
\text { Trust level }\end{array}$ & $\begin{array}{c}0.85 \\
1.000\end{array}$ \\
\hline
\end{tabular}

this case, the Confidence Index is 0.85 , which implies that all the 4 ranking procedures are $85 \%$ in concordance with the final ranking.

Trust level metric is an indicator of the reliability of the final ranking, which is very high, i.e., 100\% (1).

Overall, from the Ensemble Ranking, it can be estimated with a high confidence index and high trust level that the most feasible vehicle alternative is the Metro.

5.6. Validation of the Rankings with Experts. Having computed each of the rankings, performing a sensitivity analysis to ensure their stability, and aggregating the results with Ensemble Ranking method, the 4 vehicle modes have been ranked in the descending order based on customized preferences of the passengers filling the survey data. There is now a need to present these findings to the transportation researchers for a final whetting. A report of all the above results was sent to the research and development teams in the Road Transport Corporation to corroborate their domain knowledge about the vehicle mode applicability and the final rankings arrived at by using the multicriteria techniques.

The rankings above were corroborated with the transportation researchers in the Telangana Road Transport Corporation, and the results in Table 14 are:

It was found that the Ensemble Ranking results were consistent with the expert rankings.

This paper thus computed each factor's individual priorities influencing supply chain resilience from the relative importance values through Fuzzy AHP. From the criteria weightages and the scores assigned to each company on these criteria, the companies were ranked by TOPSIS, Fuzzy TOPSIS, EDA, and IRP. The rankings' consistency was stabilized by sensitivity analysis and aggregated to a consolidated Ensemble Ranking system with high trust level and confidence index. The final rankings were also successfully whetted by domain experts and the final ranking reveals that the Metro is the most feasible alternative. The implications are discussed below:

\section{Implications of the Study}

6.1. Theoretical Contributions to the Study. In this paper, a novel hybrid multicriteria model is developed to choose the most feasible transport modes wherein the Fuzzy Analytical Hierarchy Process is used to compute the weights of criteria or factors considered by passengers to select the transport mode. The weights are then utilized to rank the transport modes for which three multicriteria ranking models, namely,
TOPSIS, Fuzzy TOPSIS, and EDA are adopted. The rankings are further granularly analyzed using sensitivity analysis, which examines the stability of the ranking and the sensitivity impact of criteria on the ranking system. Furthermore, the results are validated by IRP and experts. The analysis reveals that the Metro train transport mode is consistently preferred in the top 2 alternatives, while other alternatives are sensitive to the variation in weights of the criteria adopted.

Therefore, this study employs a hybrid and robust multicriteria model, which can be recalibrated and adapted in different contexts to determine the most feasible transport mode.

6.2. Implications for Practice. The implications for practice are twofold: first on the transport policy and management, and second on the passengers.

6.2.1. Managerial and Policy Implications. From the weightage computation results using the Fuzzy AHP, it is found that Political factors are the most important, followed by Social factors and Technological factors and then Economic Factors. This implies that, for the transport authority to implement a new transport mode (in this case, metro), the political clearances need to be obtained, and the political party in power should ratify the launch of a new transport mode. Second, the authority should analyze the impact of the latest transport mode on society, particularly the commuters. Subsequently, the technological know-how is to be examined by consulting operations research experts and engineers to design a transport mode with state-of-the-art technology. The economic feasibility is to be analyzed, keeping in mind the price-sensitive market of India and the commuters' economic conditions. Environmental considerations and sustainability need to be taken care of, keeping in mind the commuter's perspective.

The subcriteria weight analysis reveals that the transport authority needs to overcome the major barrier of Political Instability (Political Factor). Consequently, assuring the Safety (Social Factor) of the commuters is of high importance. The authorities need to comply with the Government policies (Political Factor) and take care of technological factors like Fuel efficiency (Technological Factor) by designing state-of-the-art transport systems in consultation with technology experts. Overall, the transport authorities need to analyze factors like safety, government policies, and technological factors like fuel efficiency for ensuring the successful implementation of the new transport mode. 
TABle 14: Comparison of final experts' ranking with the above-computed rankings.

\begin{tabular}{lcccccc}
\hline \multirow{2}{*}{ Alternative } & \multicolumn{3}{c}{ Ranking } & \multicolumn{2}{c}{ Validation } \\
& TOPSIS & EDA & Fuzzy TOPSIS & IRP & Ensemble ranking & Domain expert validation \\
\hline Metro & 1 & 1 & 1 & 1 & 1 & 1 \\
Public bus & 2 & 2 & 2 & 2 & 4 & 2 \\
Bike & 3 & 4 & 4 & 4 & 3 & 4 \\
Car & 4 & 3 & 3 & 3 & 3 \\
\hline
\end{tabular}

Considering the consistent performance of the metro train alternative with respect to the ranking models (TOPSIS, Fuzzy TOPSIS, EDA, and IRP), sensitivity analysis results, and validation results from Ensemble Ranking and transportation experts, it is recommended to advocate and spread awareness about the need to use the Metro as a costeffective, environmental-friendly, safe, and fast mode of transport among all the employees, students, and other citizens.

The policy implications are thus outlined below:

Firstly, regularization and expansion of Metro routes are recommended, especially across busy and high traffic-density routes where other conventional modes of transport like Bus, Car, and Bike cause traffic jams.

Secondly, there is a need to define the hierarchy and areas of operation for the integrated use of an unconventional transport mode like the Metro and other defined conventional transport modes since eliminating the conventional transport modes with immediate action is not feasible. Busier and long-distance routes can be well-connected by the Metro. In contrast, for shorter distances and across traffic-sparse routes, conventional modes can continue to be operated to secure the livelihood of the staff of the Public bus corporations and for Bike and Bus drivers.

Thirdly, route planning can be optimized, and the use of pooling operations, especially for Cars, can be promoted to minimize the environmental damage caused by the use of private modes of transport like Cars.

Inter-modal transfer hubs can be initiated where for each metro station, a Car-pooling system can be arranged for short distances by using Car rental solutions. For instance, if a passenger (an employee of a private IT organization) needs to commute from Uppal (an eastern suburb locality in Hyderabad) to Hitech City (IT hub of the city), a Metro line from Nagole (near Uppal) to Miyapur (around 5 kilometers from Hitech City) can be routed. At the Miyapur Metro station, a Carpool rental, or a Bike or, for high traffic dense routes, a Bus can be arranged at nominal prices to safely drop the passengers at the desired location, i.e., Hitech city. This may lead to a win-win situation in the form of a publicprivate partnership for the Metro staff, Bus drivers, Car rental drivers, and Bike rental drivers; thus, they can collaboratively provide transport solutions to the people of Hyderabad.

6.2.2. Implications for the Society and Passengers. Passengers, primarily working professionals and students, are motivated by the results to prefer the Metro to save commuting time, for safety, and for achieving cost and fuel efficiency. Metro is particularly useful for long-distance commuting from one end of the city to the other, and proves to be politically noncontroversial, economically viable, socially safe, healthy, technologically fuel-efficient, legal, and ecologically sustainable.

\section{Conclusion}

This paper devises a hybrid Fuzzy AHP-TOPSIS/Fuzzy TOPSIS/EDA/IRP/Ensemble Ranking model to evaluate which vehicle alternative to choose from, keeping in mind the passenger preferences. The study focuses on the Indian metro city context with Hyderabad as a case in point.

It is hoped that this paper would benefit the passengers, transport authorities, and researchers for constructing an intelligent transportation selection model based on factors prioritized by the stakeholders using a novel hybrid multicriteria model. The simulation model provides a platform to weigh different factors developed from the PESTLE framework and select the most feasible mode of transportation. This paper is confined to a particular metropolitan city in the southern part of India, and the alternative ranking is prescribed keeping in view the local requirements of passengers and taking into consideration the relative traffic densities of the particular city of Hyderabad. However, the factors considered to evaluate the most suitable vehicle mode are applicable for all city and country scenarios, and the model can be thus recalibrated and extended to all study areas(cities) in the world with different traffic and different population densities.

The hybrid multicriteria model is developed in the context of Indian metropolitan cities, and no prior work of the subject matter dealt in this paper is found in existing studies. The subcriteria considered were the vehicle selection problem: Political Stability, Government Policy, Duties and Taxes, Economic Growth, Unemployment, Cost Efficiency, Health, Safety, Security, Maintenance, Fuel Efficiency, Restricted Movement, and Pollution. These factors were taken into account to rank the vehicle modes in the descending order. The relative importance of the criteria and alternatives is further analyzed using sensitivity analysis and is validated by Ensemble Ranking and expert decision-makers. Thus, this paper demonstrates a methodology to determine an appropriate transportation mode, keeping in mind the passengers' personalized preferences.

\section{Data Availability}

The data used to support the findings of this study are available from the corresponding author upon request. 


\section{Conflicts of Interest}

The authors declare no conflicts of interest.

\section{References}

[1] "Mordor intelligence report transportation industry in India -analysis of growth, trends and forecast (2020 - -2025)," 2020, https://www.mordorintelligence.com/industry-reports/ analysis-of-transportation-industry-in-india.

[2] S. Nasrin, "Private uUniversity sStudents' mMode cChoice bBehaviour for tTravel to uUniversity: aAnalysis in the cContext of dDhaka cCity," in Transportation Research, pp. 299-310, Springer, Singapore, 2020.

[3] P. Vincke, "Recent progresses in multicriteria decision-aid," Rivista di Matematica per le scienze Economiche e Sociali, vol. 17, no. 2, pp. 21-32, 1994.

[4] K. Govindan, S. Rajendran, J. Sarkis, and P. Murugesan, "Multi criteria decision making approaches for green supplier evaluation and selection: a literature review," Journal of Cleaner Production, vol. 98, pp. 66-83, 2015.

[5] M. Rabbani, M. Davoudkhani, and H. Farrokhi-Asl, "A new multi-objective green location routing problem with heterogonous fleet of vehicles and fuel constraint," International Journal of Strategic Decision Sciences (IJSDS), vol. 8, no. 3, pp. 99-119, 2017.

[6] M. G. Sobhani, M. N. Imtiyaz, M. S. Azam, and M. Hossain, "A framework for analyzing the competitiveness of unconventional modes of transportation in developing cities," Transportation Research Part A: Policy and Practice, vol. 137, pp. 504-518, 2020.

[7] G. Khatwani and P. R. Srivastava, "Employing group decision support system for the selection of internet information search channels for consumers," International Journal of Strategic Decision Sciences (IJSDS), vol. 6, no. 4, pp. 72-93, 2015.

[8] M. Tajadod, M. Abedini, A. Rategari, and M. Mobin, "A comparison of multi-criteria decision making approaches for maintenance strategy selection (a case study)," International Journal of Strategic Decision Sciences (IJSDS), vol. 7, no. 3, pp. 51-69, 2016.

[9] P. Christiansen, "The effects of transportation priority congruence for political legitimacy," Transportation Research Part A: Policy and Practice, vol. 132, pp. 61-76, 2020.

[10] K. Chen, X. Xin, X. Niu, and Q. Zeng, "Coastal transportation system joint taxation-subsidy emission reduction policy optimization problem," Journal of Cleaner Production, vol. 247, p. 119096, 2020.

[11] K. Kavta and B. Adhvaryu, "Walking and bBicycling to sSchool-uUnderstanding the iImpact of sSocio-economic fFactors and bBuilt eEnvironment," in Transportation Research, pp. 275-285, Springer, Singapore, 2020.

[12] T. Zhou and J. Zhang, "Behavioral research on transport and energy in the context of aviation," in Transport and Energy Research, pp. 279-294, Elsevier, Amsterdam, Netherlands, 2020.

[13] E. Kurtuluş and İ. B. Çetin, "Analysis of modal shift potential towards intermodal transportation in short-distance inland container transport," Transport Policy, vol. 89, pp. 24-37, 2020.

[14] S. Wang, J. Wang, and F. Yang, "From willingness to action: dDo push-pull-mooring factors matter for shifting to green transportation?" Transportation Research Part D: Transport and Environment, vol. 79, Article ID 102242, 2020.
[15] Y. Tyrinopoulos and C. Antoniou, "Review of factors affecting transportation systems adoption and satisfaction," in Demand for Emerging Transportation Systems, pp. 11-36, Elsevier, Amsterdam, Netherlands, 2020.

[16] S. Stoilova, "Methodology for mMulti-criteria sSelection of tTransportation tTechnology in tTransport nNetwork," in Modelling of the Interaction of the Different Vehicles and Various Transport Modes, pp. 1-103, Springer, Cham, Switzerland, 2020.

[17] A. S. Krishna, J. Thomas, and P. N. Salini, "Estimating mModal sShift of hHome-bBased wWork tTrips dDue to the dDevelopment of kKochi mMetro and rReduction in fFuel cConsumption and eEmissions," in Transportation Research, pp. 229-242, Springer, Singapore, 2020.

[18] A. T. Onstein, M. Ektesaby, J. Rezaei, L. A. Tavasszy, and D. A. van Damme, "Importance of factors driving firms' decisions on spatial distribution structures," International Journal of Logistics Research and Applications, vol. 23, no. 1, pp. 24-43, 2020.

[19] Z. Kou, X. Wang, S. F. A. Chiu, and H. Cai, "Quantifying greenhouse gas emissions reduction from bike share systems: a model considering real-world trips and transportation mode choice patterns," Resources, Conservation and Recycling, vol. 153, p. 104534, 2020.

[20] X. Liu, L. Gao, A. Ni, and N. Ye, "Understanding bBetter the iInfluential fFactors of cCommuters' mMulti-dDay tTravel bBehavior: eEvidence from SShanghai, China," Sustainability, vol. 12, no. 1, pp. 1376-13, 2020.

[21] N. Tian, S. Tang, A. Che, and P. Wu, "Measuring regional transport sustainability using super-efficiency SBM-DEA with weighting preference," Journal of Cleaner Production, vol. 242, Article ID 118474, 2020.

[22] S. Gössling, "Integrating e-scooters in urban transportation: pProblems, policies, and the prospect of system change," Transportation Research Part D: Transport and Environment, vol. 79, Article ID 102230, 2020.

[23] N. S. Daisy, L. Liu, and H. Millward, “Trip chaining propensity and tour mode choice of out-of-home workers: evidence from a mid-sized Canadian city," Transportation, vol. 47, no. 2, pp. 763-792, 2020.

[24] D. P. Ashmore, R. Thoreau, C. Kwami, N. Christie, and N. A. Tyler, "Using thematic analysis to explore symbolism in transport choice across national cultures," Transportation, vol. 47, no. 2, pp. 607-640, 2020.

[25] R. Tarabay and M. Abou-Zeid, "Modeling the cchoice to sswitch from ttraditional mmodes to rridesourcing sservices for ssocial/recreational ttrips in Lebanon," Transportation, vol. 47, no. 4, pp. 1733-1763, 2019.

[26] J. Van Ristell, M. Quddus, M. Enoch, C. Wang, and P. Hardy, "Quantifying the transport-related impacts of parental school choice in England," Transportation, vol. 40, no. 1, pp. 69-90, 2013.

[27] M. J. Roorda, J. A. Carrasco, and E. J. Miller, “An integrated model of vehicle transactions, activity scheduling and mode choice," Transportation Research Part B: Methodological, vol. 43, no. 2, pp. 217-229, 2009.

[28] S. Jian, T. H. Rashidi, K. P. Wijayaratna, and V. V. Dixit, “A spatial hazard-based analysis for modelling vehicle selection in station-based carsharing systems," Transportation Research Part C: Emerging Technologies, vol. 72, pp. 130-142, 2016.

[29] L. Luo, Y. E. Ge, F. Zhang, and X. J. Ban, "Real-time route diversion control in a model predictive control framework with multiple objectives: tTraffic efficiency, emission 
reduction and fuel economy," Transportation Research Part D: Transport and Environment, vol. 48, pp. 332-356, 2016.

[30] X. Chen and X. Wang, "Effects of carbon emission reduction policies on transportation mode selections with stochastic demand," Transportation Research Part E: Logistics and Transportation Review, vol. 90, pp. 196-205, 2016.

[31] L. Böcker, P. van Amen, and M. Helbich, "Elderly travel frequencies and transport mode choices in Greater Rotterdam, Tthe Netherlands," Transportation, vol. 44, no. 4, pp. 831-852, 2017.

[32] A. A. Campbell, C. R. Cherry, M. S. Ryerson, and X. Yang, "Factors influencing the choice of shared bicycles and shared electric bikes in Beijing," Transportation Research Ppart C: Emerging Technologies, vol. 67, pp. 399-414, 2016.

[33] W. L. Chee and J. L. Fernandez, "Factors that influence the choice of mode of transport in Penang: aA preliminary analysis," Procedia-Social and Behavioral Sciences, vol. 91, pp. 120-127, 2013.

[34] I. J. Donald, S. R. Cooper, and S. M. Conchie, "An extended theory of planned behaviour model of the psychological factors affecting commuters" transport mode use," Journal of Environmental Psychology, vol. 40, pp. 39-48, 2014.

[35] M.intesnot Gebeyehu and S.hin-EiE. Takano, "Diagnostic eEvaluation of pPublic tTransportation mMode cChoice in Addis Ababa," Journal of Public Transportation, vol. 10, no. 4, pp. 27-50, 2007.

[36] M. Kamargianni, S. Dubey, A. Polydoropoulou, and C. Bhat, "Investigating the subjective and objective factors influencing teenagers' school travel mode choice--An integrated choice and latent variable model," Transportation Research Part A: Policy and Practice, vol. 78, pp. 473-488, 2015.

[37] R. Madhuwanthi, A. Marasinghe, JR. P. C. J. RajapakseRPC, A. D. Dharmawansa, and S. Nomura, "Factors iInfluencing to tTravel bBehavior on tTransport mMode cChoice," International Journal of Affective Engineering, vol. 15, no. 2, pp. 63-72, 2016.

[38] B. B. Majumdar, S. Mitra, and P. Pareekh, "Methodological framework to obtain key factors influencing choice of bicycle as a mode," Transportation Research Rrecord, vol. 2512, no. 1, pp. 110-121, 2015.

[39] G. Santos, H. Maoh, D. Potoglou, and T. von Brunn, "Factors influencing modal split of commuting journeys in mediumsize European cities," Journal of Transport Geography, vol. 30, pp. 127-137, 2013.

[40] D. Simons, P. Clarys, I. De Bourdeaudhuij, B. de Geus, C. Vandelanotte, and B. Deforche, "Why do young adults choose different transport modes? A focus group study," Transportation Policy, vol. 36, pp. 151-159, 2014.

[41] C. Diderich, "Understanding the iIndustry eEnvironment and iIts iImplications to sStrategy," in Design Thinking for Strategy, pp. 79-92, Springer, Cham, Switzerland, 2020.

[42] C. L. Hwang and K. Yoon, "Multiple criteria decision making," Lecture Notes in Economics and Mathematical Systems, vol. 186, pp. 58-191, 1981.

[43] M. Mohammadi and J. Rezaei, "Ensemble ranking: aAggregation of rankings produced by different multi-criteria decision-making methods," Omega, vol. 96, Article ID 102254, 2020.

[44] R. K. Mavi, N. Zarbakhshnia, and A. Khazraei, “A fuzzy DEMATEL analysis of cultural variables in traffic rules violation," International Journal of Strategic Decision Sciences (IJSDS), vol. 8, no. 4, pp. 69-85, 2017.

[45] S. A. Mc Leod, "Observation methods," Available at: https:// www.simplypsychology.org/observation.html, 2015.
[46] O. Taylan, D. Kaya, and A. Demirbas, "An integrated multi attribute decision model for energy efficiency processes in petrochemical industry applying fuzzy set theory," Energy Cconversion and Mmanagement, vol. 117, pp. 501-512, 2016.

[47] G. Ljubomir, D. Pamučar, S. Drobnjak, and H. R. Pourghasemi, "Modeling the spatial variability of forest fire susceptibility using geographical information systems and the analytical hierarchy process," in Spatial Modeling in GIS and R for Earth and Environmental Sciences, pp. 337-369, Elsevier, Amsterdam, Netherlands, 2019.

[48] P. Eachempati and P. R. Srivastava, "Personalized eElective sSelection: aA mMulti-cCriteria pPerspective in aAcademia," International Journal of Strategic Decision Sciences (IJSDS), vol. 10, no. 4, pp. 43-63, 2019.

[49] T. Singh, A. Patnaik, G. Fekete, R. Chauhan, and B. Gangil, "Application of hybrid analytical hierarchy process and complex proportional assessment approach for optimal design of brake friction materials," Polymer Composites, vol. 40, no. 4, pp. 1602-1608, 2019.

[50] Y. Wind and T. L. Saaty, "Marketing applications of the analytic hierarchy process," Management Science, vol. 26, no. 7, pp. 641-658, 1980.

[51] M. B. Ayhan, "A ffuzzy AHP aapproach for ssupplier sselection pproblem: a ccase sstudy in a gear mmotor ccompany," 2013, https://arxiv.org/abs/1311.2886 arXiv preprint arXiv:1311.2886.

[52] O. Gogus and T. O. Boucher, "Strong transitivity, rationality and weak monotonicity in fuzzy pairwise comparisons," Fuzzy Sets and Systems, vol. 94, no. 1, pp. 133-144, 1998.

[53] A. Calik, "A multi-criteria evaluation for sustainable supplier selection based on fuzzy sets," Business and Economics Research Journal, vol. 10, no. 1, pp. 95-113, 2020.

[54] F. Cavallaro, E. K. Zavadskas, D. Streimikiene, and A. Mardani, "Assessment of concentrated solar power (CSP) technologies based on a modified intuitionistic fuzzy TOPSIS and trigonometric entropy weights," Technological Forecasting and Social Change, vol. 140, pp. 258-270, 20198.

[55] Y. Wind and T. L. Saaty, "Marketing applications of the analytic hierarchy process," Management Science, vol. 26, no. 7, pp. 641-658, 1980.

[56] S. Zhang, H. Gao, G. Wei, Y. Wei, and C. Wei, "Evaluation based on distance from average solution method for multiple criteria group decision making under picture 2-tuple linguistic environment," Mathematics, vol. 7, no. 3, p. 243, 2019.

[57] Ž. Stević, M. Vasiljević, A. Puška, I. Tanackov, R. Junevičius, and S. Vesković, "Evaluation of suppliers under uncertainty: a multiphase approach based on fuzzy AHP and fuzzy EDAS," Transport, vol. 34, no. 1, pp. 52-66, 2019.

[58] B. E. Narkhede, R. Raut, B. Gardas, H. T. Luong, and M. Jha, "Selection and evaluation of third party logistics service provider (3PLSP) by using an interpretive ranking process (IRP)," Benchmarking: An International Journal, vol. 24, no. 6, pp. 1597-1648, 2017.

[59] D. Sushil, "Interpretive ranking process," Global Journal of Flexible Systems Management, vol. 10, no. 4, pp. 1-10, 2009.

[60] G. Choudhury, "Demystifying India’s poverty line: here's everything you need to know," 2015, https://www.hindustantimes.com/ business/demystifying-india-s-poverty-line-here-s-everythingyou-need-to-know/story-43vy1sQ7LrCZuezTakDnkM.html.

[61] H. Devulapalli and G. Agrawal, "Mapping bus transit services in Hyderabad-- an illustrative example of the use of open geospatial data," Transportation Research Procedia, vol. 25, pp. 4196-4206, 2017. 
[62] T. S. Babu, K. V. A. Kumar, and P. S. C. Teja, "Implementation of sSpeed fFlow mModels for the aAnalysis of sStreet pParking in Hyderabad," The International Journal of Analytical and Experimental Modal Analysis, vol. 12, no. 1, pp. 1076-1088, 2020.

[63] R. T. C. Baski, "ac bbus ffares to gget ccheaper in Hyderabad. Telangana today," 2020, https://telanganatoday.com/ rtc-ac-bus-fares-to-get-cheaper-in-hyderabad.

[64] "TNM staff Hyderabad metro sees record 4.6 llakh ppassengers on New Year's Eve. The News Minute," 2020, https:// www.thenewsminute.com/article/hyderabad-metro-sees-reco rd-46-lakh-passengers-new-years-eve-115183.

[65] U. S. Mahtani and C. P. Garg, "An analysis of key factors of financial distress in airline companies in India using fuzzy AHP framework," Transportation Research Part A: Policy and Practice, vol. 117, pp. 87-102, 2018. 